Portland State University

PDXScholar

2016

\title{
What do Physicians Know about Global Plans to Stop Tuberculosis? Interviews from Five Countries
}

Hannah Johnson

Portland State University

Follow this and additional works at: https://pdxscholar.library.pdx.edu/honorstheses

Let us know how access to this document benefits you.

\section{Recommended Citation}

Johnson, Hannah, "What do Physicians Know about Global Plans to Stop Tuberculosis? Interviews from Five Countries" (2016). University Honors Theses. Paper 257.

https://doi.org/10.15760/honors.242

This Thesis is brought to you for free and open access. It has been accepted for inclusion in University Honors Theses by an authorized administrator of PDXScholar. Please contact us if we can make this document more accessible: pdxscholar@pdx.edu. 
What do Physicians Know about Global Plans to Stop Tuberculosis? Interviews from Five Countries

by

Hannah Johnson

An undergraduate honors thesis submitted in partial fulfillment of the requirements for the degree of

Bachelor of Science

in

University Honors

and

General Science

Thesis Adviser

Dr. Richard Lockwood

Portland State University 
Table of Contents

\begin{tabular}{lc}
\hline \multicolumn{1}{c}{ Section } & Page \\
\hline Chapter 1: Introduction & $3-5$ \\
\hline Chapter 2: Review of the Literature & \\
Tuberculosis & $6-11$ \\
Development & $11-13$ \\
Mixed Methods & 13 \\
Sampling & $13-14$ \\
Data Sources & $14-15$ \\
Interviews & $15-16$ \\
\hline
\end{tabular}

Chapter 3: Methodology

Research Design 17

$\begin{array}{lr}\text { Sampling } & 18-20\end{array}$

Analysis Plan 20-24

Chapter 4: Results and Analysis

Quantitative Data 25-26

Quantitative Analysis 26-33

Core Narrative Analysis 33-55

Chapter 5: Conclusion

Physician Knowledge $\quad 56-60$

Bibliography 61-62

Appendix A

Core Narratives 


\section{Chapter 1: Introduction}

\section{Background}

Drug-resistant tuberculosis (DR-TB) has been described as an urgent global health priority, yet it receives little attention. Until bedaquiline was approved for treatment in 2012 , it had been forty years since a new drug had been developed for tuberculosis (TB) (Mahajan 2013). This time lapse illustrates a common problem; the lack of attention paid to diseases that minimally affect high income countries. It can be agreed this inattention has bad consequences. The widespread misuse of ineffective antibiotics for DR-TB has caused harm by accelerating the development of drug resistant strains.

There now exists two tiers of DR-TB: multidrug-resistant tuberculosis (MDR-TB) and extensively drug-resistant tuberculosis (XDR-TB). It is expensive to treat both MDR-TB and XDR-TB because proper treatment involves thousands of pills and hundreds of shots administered over the course of a two year period. Such costly treatment conflicts with cost-effective analysis, which is the prevailing ideology in global health (Médecins Sans Frontières 2013). This approach calculates the net gain in health, or reduction in disease burden, in relation to the cost of treatment (World Bank 1993). A 50\% treatment success rate for DR-TB further impedes the cost-effectiveness of treating DR-TB (Médecins Sans Frontières 2013).

To alleviate the burden of TB, global plans have been in effect since 2000. Goal Six of the Millennium Development Goals (MDGs) was designed to halt and reverse the incidence, prevalence, and death rates associated with HIV/AIDS, tuberculosis, and malaria by the end of 2015 (World Health Organization 2010). In addition, the Global Plan to Stop TB (Stop TB) planned to reduce both the prevalence and mortality rates by $50 \%$ by the end of 2015 , and to eradicate the disease by 2050 (World Health Organization 2010). Since the MDGs ended in 2015 and Stop TB released a new plan in 2016, it is necessary to evaluate the impact of both plans, between the years 2000 and 2015, on countries with a nonzero prevalence of TB. 
Focusing on DR-TB burden adds an additional layer of assessment that can be used to measure the impact of global plans for TB. Bedaquiline is the most recent drug developed for DR-TB. Bedaquiline is an antibiotic that blocks an ATP synthesizer in bacterial cells (Monedero 2016). Several, successful compassionate use trials were conducted before bedaquiline received FDA approval in 2012 (Monedero 2016). Currently, bedaquiline is only approved for treatment administered over the course of six months. It interacts poorly with another drug known as clofazimine, but is generally successful in treating XDR patients (Monedero 2016). Distribution was finally approved in April 2014. By the end of 2014, 43 countries were reportedly given access to the drug (World Health Organization 2015). Organizations lobbying for expanded use of bedaquiline list several steps that need to be taken for bedaquiline: bedaquiline needs to be registered in each country, treatment guidelines in country need to be updated to reflect World Health Organization (WHO) recommendations for bedaquiline as an essential medicine, and adverse effects need to be monitored (Médecins Sans Frontières 2016). Since bedaquiline has limited distribution, and it represents an important new drug in DR-TB treatment, whether a country has access to bedaquiline is important to contextualizing the impact of global program on the most concerning forms of DR-TB.

While TB burden is monitored for both the MDGs and Stop TB, using country level indicators, this research proposes evaluation at the physician level. As the global health discipline has evolved over time, doctors have proven themselves important advocates for social change. Médecins Sans Frontières and Partners in Health have shown that doctors can successfully advocate for their patients. Both organizations believe technology can be used to cure impoverished people's diseases at the same time that poverty is eradicated. This is in opposition to the "Luddite trap," which says that poverty must be eliminated before disease is eliminated (Farmer 2003). The trap is similar to cost-effective analysis because it denies care for diseases that affect impoverished people. Doctors must overcome both costeffective analysis and the "Luddite trap" to show that disease can be treated successfully in any setting. 
If physicians advocate for their patients, and provide evidence for successful treatment in resource poor settings, global support should increase for neglected diseases like TB.

However, physicians are not without limitations. Beyond the doctor-patient relationship, physicians must also work with global entities like the WHO and the UN. As mentioned before, both the WHO and the UN created the MDGs and Stop TB. The MDGs and Stop TB outline the distribution of funds and technology that help countries meet their health and development goals. If physicians are knowledgeable about global programs, they can understand the best way to ask for support. The challenge is that global programs are constantly changing. Because of this, it is necessary to recognize that a physician's agency may be limited by the information distributed to them about global programs. It is possible that the WHO and the UN limit information flow. Alternatively, physicians may limit themselves by denying their professional duty to stay up-to-date. In the age of the internet, information can be accessed by anyone, anywhere. Assuming doctors have agency, that they are pivotal to global health programs, and in an effort to understand limitations on the effectiveness of global programs, this research will address the following question: What do physicians know about global programs for TB?

Moving forward, Chapter 2 will cover the background literature for theory as well as constructs \& methods in this study. Chapter 3 will present the methodology, including research design, sampling, and analysis plan. Chapter 4 will cover results and analysis. Chapter 5 will provide interpretations and put the results in context. 


\section{Chapter 2: Review of the Literature}

\section{Tuberculosis}

Today, the 2015 Global Tuberculosis Report states that "TB now ranks alongside HIV as a leading cause of death worldwide" (World Health Organization 2015, 1). In 2014, mortality was 1.5 million and incidence 6 million (World Health Organization 2015). Of the 480,000 estimated DR-TB cases in 2014, only $50 \%$ of patients were successfully treated (World Health Organization 2015). Funding gaps for DRTB amount to $\$ 1.4$ billion for implementation of existing interventions, and \$1.3 billion for research and development (World Health Organization 2015). Systematic analysis has shown that under specific circumstances MDR-TB could reverse important gains already made in combatting TB (Murray 2014). This risk imparts added urgency to replace cost-effective analysis and to assert the importance of eradicating all forms of TB.

Because global disease burden can be analyzed in more specific terms at the population level, TB must be epidemiologically evaluated. Epidemiology is the study of "disease and death, and their determinants and consequences in population groups" (Omran 1971, 509). It is an area of study that can be used to predict population change, and help refine and build population theory (Omran 1971). As epidemiology relates to TB, there are many variables that affect how TB exists and spreads through populations. Most notably, TB is a disease of the poor.

The relationship between TB and poverty is complex. Early on in the US, TB was specifically described as a disease of ethnic minorities (Spence 1993). Although TB was nearly eradicated from the US in the 1970s, HIV led to a resurgence of the disease in the 1980s (Sepkowitz 1996). Up until then the relationship between TB and poverty was thought to strictly result from malnutrition (Spence 1993). Later, research found that factors independently associated with tuberculin positivity included crack cocaine use, foreign birthplace, African American race, older age, alcoholism, and HIV status (Howard 
2002). Collectively, these factors highlighted the intersection between TB, economic status, and health behaviors.

Building on the complexities involved in socioeconomic status and comorbidity, TB burden is complicated by transmission and diagnosis. TB infection is commonly found in the lungs. It causes difficulty breathing and coughing. It can be diagnosed both clinically and bacteriologically. Bacteriologic diagnosis is confirmed from a sputum sample expelled from the lungs. Tests that can be used to identify the TB bacterium include smear microscopy, culture, or Xpert MTB/RIF testing (World Health Organization 2013). Clinical diagnosis of DR-TB is confirmed when a patient has received a full course of treatment and lung $\mathrm{x}$-ray abnormalities persist. This can be after months of receiving ineffective treatment. MDR-TB is treated with four first line drugs, three second line injectable drugs, three quinolone grade medications, and three other second line drugs (World Health Organization 2009). TB transmission decreases when patients cover their cough, wear masks over their mouth, when ultraviolet light is used to sterilize air in clinical settings, and when negative pressure is used to ventilate patients' rooms (Sepkowitz 1996). In general, TB transmission rates decrease when overcrowding is decreased and social conditions improve (Spence 1993).

In addition to transmission and diagnosis, stigma has made TB difficult to treat. A study conducted at the University of Texas illuminated the social stigma associated with TB in the US. TB was described by TB patients as an isolating illness because patients' families often shunned them (Kelly 1999). Furthermore, patients identified themselves as disease vectors; they felt that they had to be secretive about their disease (Kelly 1999). On top of this, patients that struggled with TB stigma were often labeled as noncompliant by their community healthcare workers (Kelly 1999). In response to this, the study advised public health professionals to recognize the complexity of each patients experience so that healthcare workers built effective relationships with their patients (Kelly 1999). Essentially, 
treatment success increased when stigma was recognized as a variable that affected patients' experiences with TB.

MDR-TB has been studied since the mid-twentieth century (Farmer 2013). Strategies for controlling MDR-TB were first introduced in the literature in the 1990s (Farmer 2013). Early treatment plans were developed for DR-TB after outbreaks occurred in the US: diagnosis with mycobacterial culture and drug susceptibility testing, use of second-line anti-tuberculosis agents, infection control, and directly observed ingestion of medications (Farmer 2013). These treatment protocols were standardized by the Center for Disease Control and Prevention (CDC) in 1992 (Farmer 2013). In 1994 the WHO adopted Directly Observed Treatment (DOTs) protocol for all first line, MDR-TB drugs (Abdel 1994). Just before this, DOTs was deemed cost-effective in the World Bank's 1993 World Development Report (WDR) (World Bank 1993). All this work precedes the development of XDR-TB, which was not introduced into the literature until 2005 (Grant 2008).

Cost-effective analysis has been problematic ever since its introduction in the 1993 WDR. The WDR was the first publication to use the Disability Adjusted Life Year (DALY) as a measurement for global disease burden, and the effectiveness of health interventions as indicated by reductions in disease burden (World Bank 1993). DALYs calculate the present value of the future years of disabilityfree life that are lost as the result of the premature deaths or cases of disability occurring in a particular year (World Bank 1993). This posed a problem for TB cases that required more expensive medication for treatment. DR-TB patients that were not cured by DOTs were re-treated with the same first line drugs that failed to cure them (Farmer 2013). The WHO said effective treatment was not possible in resource poor countries because it was too expensive, but the more important problem was access to proper treatment. In the United States and other high income countries, first line drugs were not used to retreat patients that were exhibiting drug-resistance. Because they could access the appropriate drugs, high income countries standardized costlier treatment (Farmer 2013). 
At this time, Farmer and his colleagues began testing treatment protocol on patients that had been deemed problem patients in resource poor Peru (Farmer 2013). The Peruvian branch of Partners in Health created a DOTs-Plus program specifically for MDR-TB cases. DOTs-Plus added second line medications, monitoring with sputum culture, drug-susceptibility testing, and directly observed individualized therapy to the existing DOTs regimen (Farmer 2013). The program had an $83 \%$ cure rate, but the WHO did not endorse DOTs-Plus until the late 1990s; Partners In Health and the CDC had to encourage the WHO to adopt it (Farmer 2013).

Building on the DOTs-Plus success, the Green Light Committee (GLC), a multi-institutional partnership launched by the WHO, strategized ways to reduce the cost of second-line tuberculosis drugs by $98 \%$ (Farmer 2013). They successfully did so in the years 1997-1999 (Farmer 2013). 16,300 patients were approved for full-course second-line therapy in 2004 (Farmer 2013). This increased to 46,300 patients in 2008 (Farmer 2013). Unfortunately, approval did not coincide with implementation. Between 2000 and 2009 of the more than 60 thousand approved cases, 20 thousand were treated with medicines made accessible by the GLC (Farmer 2013). Still 1.5 million new MDR-TB cases were detected and 1.5 million people died (Farmer 2013). The WHO did not officially incorporate proper MDR-TB treatment protocol until 2006 (Farmer 2013).

Quantitative instruments can be useful for measuring global disease burden but there can be harmful consequences if these instruments are used uncritically (Farmer 2013). Farmer theorizes that unwavering adherence to the old DOTs protocol and cost-effective analysis are what caused the DR-TB epidemic that exists today (Farmer 2013). Also, clinical trials for essential medicines have been carried out in developing countries, but later denied to those countries that were using them because the patented version is redistributed through market mechanisms (Farmer 2013). The economist Jeffrey Sachs said that "excess disease burden can be controlled at fairly low cost, even before poverty itself is 
relieved," but barriers to reducing DR-TB burden continue to exist in global health politics (Sachs 2012, 1).

In 2000, world leaders from 189 countries met at the United Nations (UN) general assembly to develop the United Nations Millennium Development Declaration (United Nations 2000). The declaration was meant to "ensure that globalization becomes a positive force for all the world's people" (United Nations 2000). It would be accomplished by completing eight goals: eradicate extreme poverty and hunger, achieve universal primary education, promote gender equality and empower women, reduce child mortality, improve maternal health, combat HIV/AIDS and other diseases, ensure environmental sustainability, and develop global partnership for development (United Nations 2016). Tasked with completing these eight development goals, the global community collectivized under the idea of creating a better world.

Goal six of the MDGS was designed to combat HIV/AIDS, malaria, and other diseases (United Nations 2016). MDG six was supposed to affect TB via Target 6c, Indicator 6.9, and Indicator 6.10. Target 6.C was designed to halt and reverse the incidence of major diseases by 2015 (World Health Organization 2010). Indicator 6.9 specifically addressed the incidence, prevalence, and death rates associated with TB (World Health Organization 2010). Indicator 6.10 sought to change the proportion of TB cases detected and cured under DOTs (World Health Organization 2010).

The Stop TB Partnership was established in 2000 to complement MDG 6 (World Health Organization 2010). Stop TB included more specific statistical targets for MDG 6: by 2015 reduce prevalence and death rates by $50 \%$, compared to their levels in 1990, and by 2050 reduce global TB incidence to one case per 1 million population per year (World Health Organization 2010). Originally this was measured against a $70 \%$ case detection rate and $85 \%$ treatment rate for those detected cases, but measurement changed in 2005 (World Health Organization 2010). 70/85\% targets were removed from official MDG and Stop TB documents in 2005 (World Health Organization 2010). Case detection rate was 
no longer used for measuring success because of the $10-15 \%$ uncertainty in estimated TB incidence (World Health Organization 2010). Instead, progress was measured against the total number of cases diagnosed, notified, and treated in DOTS programs (World Health Organization 2010). Rather than compare success to projected values, global programs focused on reported cases.

Seventeen targets were used to monitor Stop TB progress, up until 2015 (World Health Organization 2010). Of the seventeen targets, two are relevant for the current research: $100 \%$ percent of laboratory confirmed MDR-TB cases started on treatment and greater than $75 \%$ treatment success rate for laboratory confirmed MDR-TB cases. Stop TB also prioritized funding, most noteworthy: raise $\$ 450$ million by 2015 , implementation of two new diagnostic technologies worldwide, development of at least two new treatment regimens for DR-TB in phase III trials, and \$86 million in funding for operational research (World Health Organization 2010). Together these seventeen targets and funding goals would serve as a "roadmap for dramatically reducing the global burden of TB by 2015" (World Health Organization 2010, v).

\section{Development}

There exists a hierarchy of wealth, status, and political power around the world. The World Bank defines this hierarchy using income quartiles: low income, lower middle income, high middle income, and high income. By accounting for a country's income level, other phenomena can be anticipated. Relevant population phenomena include the four Health Transition Theories: Demographic Transition, Epidemiological Transition, Nutrition Transition, and Health Funding Transition. Development indicators provide evidence for explaining a country's position in each Health Transition.

Although income stratification is divided into quartiles, stratification shows a continuous effect on population health. Population birth and death rates are limited by resources, population growth, and misery and vice (Malthus 1798). However, the Three Transition Theories go a step further by describing 
the continuous change that occurs when countries strengthen their economies. Demographic Transition describes that the age structure of a population changes with development. When countries accumulate greater wealth their populations transition from having many babies and many people dying to having fewer babies and fewer people dying (Malthus 1798). Second, Epidemiologic Transition states when countries Demographically Transition, their health care challenges shift from communicable disease to noncommunicable disease (Omran 1971). Improved economic status produces better healthcare. Aging and overconsumption follow in the Nutrition Transition: a population shift from undernutrition and nutrient deficiencies, to both undernutrition and obesity, to primarily obesity (Popkin 1944). This is followed by the fourth and final transition: Health Financing Transition. Health Financing Transition describes an increase in health funds as a result of development (Fan 2014).

Because the four Health Transition Theories has a continuous effect on population health, disease burden does not always match a country's income quartile. There are many possible transition phases, each with different health challenges. A country can move from lower middle income to high middle income, and maintain a high communicable disease burden. It is not always straightforward to reason why countries have unusual disease burden in relation to their income level. However, development indicators are useful tools for describing transition variance.

Development indicators, monitored by the WHO and the World Bank, are used to measure development progress. Development indicators are statistical benchmarks collected from official international sources that can help describe the strengths and weaknesses of countries as they develop (World Bank 2010). Oftentimes indicators are reported as a fraction or percentage of the population that exhibits a particular trait. For example, poor countries often have high birth rates, high death rates, short life expectancy, and high disease and mortality rates from communicable disease (Omran 1971). Conversely, high income countries have low birth rate, lower death rates, longer life expectancy, and greater disease burden from noncommunicable disease (Omran 1971). Evaluating health indicators can 
help describe the impact of development on a country's health. However, interpretation of statistical change must be multidisciplinary in order for meaningful analysis to be derived (Omran 1971).

Collectively, indicators that describe demographics, development, and health resources can explain the effects of development on health using specific population descriptors.

\section{Mixed Methods}

Recently it is more common to combine research methodologies in global health research. Farmer argues for an interdisciplinary approach that combines anthropology, sociology, history, political economy, and other resocializing disciplines with fields like epidemiology, demography, clinical practice, molecular biology, and economics (Farmer 2013). This is to create a new field of global health equity that Farmer calls a biosocial approach (Farmer 2013). Essentially a biosocial approach must incorporate mixed methodology.

Mixed methodology rejects the assumption that quantitative and qualitative data are incompatible (Morgan 2007). It encourages investigating factors that affect the transferability of knowledge into other settings (Morgan 2007). Rather than creating an all or nothing barrier, mixed methodology seeks a pragmatic approach where it is assumed that there is one real world, but that individuals have their unique interpretations of that world (Morgan 2007). Mixed methodology is embraced in this study; both secondary data and one-on-one, semi-structured interviews are combined to elucidate the connection between data and human experience.

\section{Sampling}

Country selection is based on the convenience provided by a study abroad program called Semester at Sea (SAS). This program allowed data to be collected in Japan, China, Vietnam, India, and South Africa. Each country is a member of the UN and participates in the MDGs. As such they report 
their development to the UN and other related organizations including the World Bank, the WHO, and the Central Intelligence Agency (CIA). Secondary data was made accessible by each of these organizations and was organized in Tables 1, 2, and 3.

\section{Data Sources}

The quantitative data involved in this research was purely preparatory. The main results of this research are not taken from the quantitative data. Quantitative data did lead to expectations about what the researcher would learn from the interviews across each country. It established the researcher's request to interview as legitimate based on familiarity with each host country.

Table 1 describes demographics and development indicators. It gives a general description of a country's income level. Each item is collected from the WHO, the World Bank, or the CIA. Table 1 includes population, growth rate, life expectancy, literacy rate, gross domestic product, gross domestic product growth, and human development index (HDI). Collectively, these indicators describe basic elements that correspond to a country's income, which can, in turn, affect a country's position in each of the health transitions. Low growth rate, high literacy rate, and high life expectancy will be associated with high income countries. The opposite will be associated with low income countries. HDI index, the last indicator, is the most complex. It is a mean of three dimensions: health, education, and standard of living (World Bank 2015). It can only measure part of human development, and lacks the capacity to "reflect on inequalities, poverty, human security, empowerment, etc" (World Bank 2015). Its relationship to income stratification must evolve through discussion.

Table 2 presents TB indicators. The purpose of this profile is to describe the burden of TB in each country using data collected from the WHO or the World Bank. Table 2 includes TB incidence, prevalence, mortality rate, laboratory confirmed RR-/MDR-TB cases, and percent of patients started on MDR-TB treatment. Together these indicators provide specific evidence for a country's epidemiological 
transition. High incidence, prevalence, and mortality indicate that a country has not epidemiologically transitioned. Furthermore, a high number of confirmed MDR-TB will be cause for concern. If a low percentage of those cases are started on treatment, the country in question is clearly facing difficulties with its disease burden.

Table 3 includes health resources and funding for TB. The WHO, the World Bank, or the CIA is the data source. Table 3 includes the earliest reported hospital beds per 1,000 people, the most recent reported hospital beds per 1,000 people, national TB program budget, percent funded domestically, percent funded internationally, and percent unfunded. The purpose of this table is to describe the resources available to alleviate TB burden. Independence from global programs will be recognizable by a high percentage of domestic funding. Alternatively, dependence on global programs will be indicated by a high percentage of international funding. Percent unfunded will be cause for concern.

\section{Interviews}

Semi-structured interviews are the ethnographic method of choice for this research. They provide qualitative data that can be compared with the statistical profiles. Qualitative measurements give physicians the opportunity share knowledge they believe is relevant to the study. When stimulated with a question and given time to respond, physicians can share their intellectual and political orientation towards a topic. Choosing to share or withhold information can communicate valuable information about an individual's perspective. Inaccurate information can also lend itself to valuable insights.

Interviews operate under the assumption that physicians have individual agency. Tuberculosis patients require long term support that requires strong commitment from their physicians. As demonstrated by the WHO's strict commitment to DOTs, the relationship between global health problems and the interventions launched to counter them is not always positive (Farmer 2013). Because 
Johnson 16

of this risk, global health programs must be self-critical. The goal of this research is to contribute to that self-criticism by explaining whether global plans for TB have helped physicians successfully combat TB. This will be based on the knowledge physicians have to offer about global programs. Essentially, this research evaluates the individual and the program. Familiarity with global TB program guidance gives physicians leverage to access resources made available by global programs. If physicians follow global guidance, they can say that they give great care because they follow the guidance. However, responsibility still rests on the shoulders of organizations that offer guidance, namely the WHO and the UN. 


\section{Chapter 3: Methodology}

This chapter addresses the methodology employed in this research. It describes the research design, sampling plan, and analysis plan. Research design provides a general description the data collection plan. Sampling explains how and where the researcher decided to collect data. The analysis plan explains how the secondary data and the interviews were analyzed to produce the results of this research.

\section{Research Design}

As mentioned before, this research employs a mixed methods research design. Both secondary data analysis and semi-structured interviews were used to collect data. The travel aspect of this research divided the completion of both tasks into two distinct times. Secondary data was collected in the author's own country, prior to the interviews. This was to provide the researcher with expectations for each country's demographics and development, TB burden, and health resources and funding. Secondary data also legitimized requests to interview by providing the researcher with background information about each country. The researcher could understand more about the context of each physician's work so that programmatic questions could be addressed without the physician needing to provide explanation for peripheral details. Interviews occurred at a later time in the countries of interest. Because the goal of this research is to understand what physicians know about global programs for TB, interviews comprise the primary results of this research. Secondary data did explain certain scenarios that arose during the interviews, but these explanations are not the focus of this research. Regardless of collection timing, similar criteria inform the sampling plan for both sets of data. 


\section{Sampling}

Country sampling was based entirely on the opportunity afforded by Semester At Sea. Attempts were made to sample eight countries, but subjects were only identified in Japan, China, Vietnam, India, and South Africa. As such, the country sample size is $n=5$.

Because TB is the focus of this research, physician selection was based primarily on job title. Research subjects include physicians that treat tuberculosis and/or administrators that supervise TB programs in the country of interest.

Both purposive and snowball sampling were used to identify subjects in each country. Faculty members from local universities were asked to solicit contacts. In some cases these contacts offered more relevant contacts. When subjects were identified they were asked via email if they would be willing to participate in the study. An interview was scheduled if the subject said yes. Written consent was obtained at the time of the interview.

Interview locations varied but generally took place in hospitals, clinics, and offices. To limit inconvenience the researcher met with subjects at their work place. Subjects were able to secure a private room for each interview.

While interviews were primarily conducted in hospitals, variance exists between subjects that affect the data. Public versus private employment was a random variable this study could not control due to limited access to physicians. For example, one physician involved in this research was an expat working for an NGO. The rest of the physicians worked for their respective government. However, the official position these government employees occupied varied from country to country. These titles include medical doctor in charge of TB hospital, director of the infectious disease department in a hospital, doctor in a TB and lung disease hospital, and state TB consultant.

Before each interview took place, questions were drafted to prompt the interviewee to share relevant information. Permission to record was obtained prior to the start of each interview. The first 
Johnson 19

four questions of the interview established the credentials and knowledge base of each subject: job title, length of time they worked in their position, connection to TB, and how long the interviewee worked with TB.

A series of open ended questions followed. This portion began with five, two part, core questions. Part one of each question consisted of a closed-ended question to establish whether the subject was familiar with the MDGs, Stop TB, their country's national TB program, their country's goals for TB, and what their opinion was on whether their country could effectively treat all DR-TB cases. The second part of each question was followed by an open ended question allowing the physician to explain their answer to part one. The interviewee was directed by skip patterns leading them to the next appropriate question. If yes, the next question asked for the subject's opinion. If no, the interviewer would explain the global plan in question and ask for other relevant information. The final two questions of the interview turned the subject's attention to new drugs for DR-TB. It explored their knowledge base of bedaquiline, and whether their country could access the drug. Finally the interview was closed with a general question. The interviewer asked the subject whether they wanted to share anything else.

As the interview proceeded, adjustments were made to accommodate the interviewee. Questions were reworded if respondents did not understand them. If the question was not fully answered, a follow up question was asked or the subjects' words were repeated back to them, prompting them to continue. If questions were already answered through a previous question, they were skipped altogether. Overall narrative collection was completed using Bell's approach, which is characterized by open-ended questions, minimal interruptions, and repeating phrase back to interviewers when necessary (Riessman 1993). Some physicians provided more data depending on how much they spoke. This was important due to the variety of languages reported in the sample. 
Altogether, the sampling strategy employed in this research significantly affects the generalizability of this research. Generalizability is unknown because systematic bias will be unaccounted for.

\section{Analysis Plan}

This research was designed to investigate the level of knowledge physicians have about global programs for TB. Although secondary data does not produce the primary results of this research, it will be analyzed to describe the stratification of each country involved in this research. Essentially, secondary data provides context for the interviews. After establishing context, the interviews will be analyzed qualitatively. Secondary data is only included in core narrative analysis to explain subject's explanations about global programs when necessary. Again, these explanations do not comprise the primary results of this research.

\section{$\underline{\text { Secondary Data }}$}

Three statistical profiles are included in the secondary data portion of this research. These profiles are as follows: demographics and development indicators, TB indicators, and health resources and funding. Each profile will fulfill a different analytic purpose.

Indicators included in this study are grouped into three statistical profiles. These profiles provide context by describing the effect of stratification on health. The three statistical profiles are: 1) demographics and development collected from the World Bank, Central Intelligence Agency, and United Nations; 2) TB indicators collected from the World Bank and World Health Organization; and 3) the health resources and funding collected from the World Bank, Central Intelligence Agency, and World Health Organization. 
Measures of demographics and development include 2014 population, 2014 growth rate, life expectancy at birth in total years for the year 2013, estimated adult total literacy rate for people ages 15 and above in the year 2015, GDP in USD for the year 2014, percent annual GDP growth in 2014, and HDI index for 2013. The most recent reported value was recorded for each demographic and development indicator to reflect present day values.

TB indicators includes incidence per 100,000 people including TB/HIV patients in the year 2013, prevalence rate in thousands including HIV and TB in 2013, mortality in thousands excluding HIV and TB in 2013, laboratory-confirmed RR-/MDR-TB cases in 2013, and percent of patients started on MDR-TB treatment. The most recent reported value was selected for each TB indicator to reflect present day burden.

Measures of health resources and funding for each country includes earliest reported hospital beds per 1,000 people, most recently reported beds per 1,000 people, national TB program budget in US millions for 2014, percent funded domestically, percent funded internationally, and percent unfunded. The most recently reported values were collected for each health resources and funding indicator, except for hospital beds. Two values were collected for hospital beds to show health resource change over time, as well as health care stability indicated by a longer reporting history.

\section{$\underline{\text { Interview }}$}

The interview portion of this research provides primary, qualitative data about what physicians know about global programs for TB. This is accomplished by narrativizing the interviews. Starting in Appendix A, Table 4.1, I present stories individuals told me about past actions and explain how those individuals understand those actions (Riessman 1993). The way I have chosen to present the interviews is in a series of core narratives presented and analyzed in order of occurrence (Appendix A). 
A core narrative is a reduced narrative that communicates only the core plot of a narrative (Riessman 1993). This is for the purpose of comparison (Riessman 1993). Labov's framework covers the features of a core narrative: an abstract, orientation, complicating action, and resolution to the action (Riessman 1993). Various methods can be used to apply this framework to the interviews discussed in this research. Besides the decisions I make in the coding process, I choose a direct, structural variation to this framework by avoiding Labov's use of the word abstract. Instead of identifying the initial interview question as the abstract, each question is identified as the "question" that prompted the core narrative. This is a personal decision to avoid confusion with the use of the word abstract in the larger context of scientific research.

At least six core narratives resulted from each interview. This is because there were six main questions in the interviews, and each interview was reduced to one core narrative. The interview questions were designed to be unbiased. Word choice is not meant to lead the interviewee to respond in any particular manner. While this is so, it was expected that interviewees would respond to each question with information related to the subject of each question.

Each core narrative contains the subject's orientation, or initial response, to the interview question. Information included here primarily orients the listener by establishing basic information the physician thought relevant to the question. The most notable characteristic of the orientation is that it precedes the complicating action for each narrative. It includes noteworthy information, but it is not necessarily controversial information. It provides summary information.

The complicating action is where conflict arises in each narrative. Conflict occurred differently across the narratives, and was identified after evaluating the entire narrative response to each question. In some interviews, multiple complicating actions could have been identified. Complicating actions were chosen, or considered best suited for a narrative, when the researcher considered the entirety of the 
narrative produced by each question. Reasons for coding information as a complicating action include: the physician presented an explicit problem, the physician presented a theoretical problem, or contradictory information was identified by the researcher. If only one complicating action arose, the action was coded as the complicating action.

The core narrative resolution marks each narrative's conclusion. Multiple resolutions could have been identified for each core narrative. Similar to the complicating action, resolutions were identified with the whole narrative under consideration. This was to identify the best suited resolution to each core narrative. Sometimes the resolution was a legitimate resolution to the explicit or theoretical problem identified in the complicating action. Additionally, the resolution could be a personal explanation offered by the physician to show they were done speaking about a topic. In some instances, the resolution offered a continuation of the narrative, in spite of the complicating action.

Deviations from the described core narrative outline exist in some of the core narratives. For example, additional questions that were added by the interviewer are presented as bolded questions outside the primary question. Additional questions were not answered in all of the interviews, so questions are included as they occurred. In order to maintain focus on the core narratives, some parts of the interviews are deleted. Similar to Bell's analysis of core narrative, additional features of the interviews are discussed in my analysis (Riessman 1993).

There is no objective, value-free scientific method that makes reality accessible, but I try to find useful insights in the core narratives nonetheless (Rogers 1993). The meaning I derive from the interviews arises out of a process of interaction between people: self, teller, listener and recorder, analyst, and reader (Riessman 1993). Through my efforts I try to illustrate the interpersonal context of the interview, which is the foundation of all human interaction (Riessman 1993). In this process, I recognize that I cannot truly speak for others about their beliefs (Riessman 1993). 
Johnson 24

Most importantly, my analysis is meant to promote awareness between individuals and programs. The assumptions I make about the interview subjects are not meant to reinforce false dichotomies. I will do this by supporting theoretical claims with evidence from informants' accounts and by considering alternative interpretations of the data (Riessman 1993). This means I will document interpretive statements for the benefit of the reader and for my own transparent accountability as the narrative interpreter. 


\section{Chapter 4: Results and Analysis}

This chapter contains both the results and analysis for this research. Secondary data is presented first. This is to contextualize the background established for each country prior to the interviews. Secondary data is presented in Tables 1, 2, and 3. The tables describes demographics and development indicators; TB indicators; and health resources and funding. Secondary data is analyzed by country immediately following the tables. Next, core narratives (Appendix A) are analyzed for physician knowledge about global programs for TB. This portion comprises the main results of this study. Secondary data is discussed in the core narrative analysis as necessary to support or discredit claims made by the doctors. Additionally, a short description of the interview context precedes each analysis section. Both secondary data and core narratives are presented in the same country order throughout this chapter. This reflects the order in which the interviews were completed.

\section{Quantitative Data}

Table 1: Demographics and Development Indicators

\begin{tabular}{|c|c|c|c|c|c|c|c|}
\hline Country & $\begin{array}{l}\text { Population }^{1} \\
\text { (2014) }\end{array}$ & $\begin{array}{l}\text { Growth } \\
\text { Rate }^{1} \\
(2014)\end{array}$ & $\begin{array}{l}\text { Life } \\
\text { Expectancy } \\
\text { at birth, } \\
\text { total years } \\
\text { (2013) }\end{array}$ & $\begin{array}{c}\text { Literacy rate, adult } \\
\text { total }^{2} \\
\text { (\% of people ages } \\
15 \text { and above, } \\
2015 \text { est) }\end{array}$ & $\begin{array}{c}\text { GDP }^{1} \text { (USD in } \\
2014)\end{array}$ & $\begin{array}{c}\text { GDP } \\
\text { Growth }^{1} \\
\text { (annual } \\
\% \text { 2014) }\end{array}$ & $\begin{array}{c}\text { HDI } \\
\text { Index } \\
\text { (2013) }\end{array}$ \\
\hline Japan & 127.1 million & -0.20 & 83 & 99.0 & $\$ 4.601$ trillion & 0 & 0.89 \\
\hline China & 1.364 billion & 0.5 & 75 & 96.4 & $\$ 10.36$ trillion & 7.4 & 0.719 \\
\hline Vietnam & 90.73 million & 1.1 & 76 & 94.5 & \$186.2 billion & 6.9 & 0.638 \\
\hline India & 1.267 billion & 1.2 & 66 & 71.2 & $\$ 2.067$ trillion & 7.3 & 0.586 \\
\hline South Africa & 54.00 million & 1.6 & 57 & 94.3 & $\$ 349.8$ billion & 4.6 & 0.658 \\
\hline
\end{tabular}


Table 2: TB Indicators

\begin{tabular}{|c|c|c|c|c|c|}
\hline Country & $\begin{array}{l}\text { Incidence }{ }^{1} \text { (Per } \\
\text { 100,000 people, } \\
\text { includes TB/HIV } \\
\text { patients, 2013) }\end{array}$ & $\begin{array}{l}\text { Prevalence Rate } \\
\text { (Number in } \\
\text { thousands includes } \\
\text { HIV and TB, 2013) }\end{array}$ & $\begin{array}{l}\text { Mortality }^{2} \\
\text { (Number in } \\
\text { thousands } \\
\text { excludes HIV and } \\
\text { TB, 2013) }\end{array}$ & $\begin{array}{l}\text { Laboratory- } \\
\text { confirmed RR- } \\
\text { /MDR-TB cases }{ }^{2} \\
\text { (2013) }\end{array}$ & $\begin{array}{l}\% \text { Patients } \\
\text { started on } \\
\text { MDR-TB } \\
\text { treatment }^{2}\end{array}$ \\
\hline Japan & 18 & 29 & 2.1 & 64 & - \\
\hline China & 70 & 1,300 & 41 & 4,183 & $52 \%$ \\
\hline Vietnam & 144 & 190 & 17 & 1,204 & $79 \%$ \\
\hline India & 171 & 2,600 & 240 & 23,162 & $91 \%$ \\
\hline South Africa & 860 & 380 & 25 & 26,023 & $41 \%$ \\
\hline
\end{tabular}

Table 3: Health Resources and Funding

\begin{tabular}{|c|c|c|c|c|c|c|}
\hline Country & $\begin{array}{c}\text { Earliest } \\
\text { reported } \\
\text { Hospital beds } \\
\text { per } 1,000 \\
\text { people }^{1} \text { (year } \\
\text { reported) }\end{array}$ & $\begin{array}{c}\text { Most recent } \\
\text { reported } \\
\text { beds per } \\
\text { 1,000 people } \\
\text { (year } \\
\text { reported) }\end{array}$ & $\begin{array}{l}\text { National TB } \\
\text { program } \\
\text { budget }^{3} \text { (US\$ } \\
\text { millions, } \\
\text { 2014) }\end{array}$ & $\begin{array}{c}\text { \% Funded } \\
\text { Domestically }{ }^{3} \\
\text { (2014) }\end{array}$ & $\begin{array}{c}\% \text { Funded } \\
\text { Internationally } \\
(2014)\end{array}$ & $\begin{array}{c}\% \\
\text { Unfunded }^{3} \\
(2014)\end{array}$ \\
\hline Japan & $13.7(1980)$ & 13.7 (2009) & $\$ 48$ & - & - & - \\
\hline China & $2.2(1980)$ & $3.8(2011)$ & $\$ 347$ & $78 \%$ & $3 \%$ & $19 \%$ \\
\hline Vietnam & $3.5(1980)$ & $2(2010)$ & $\$ 73$ & $9 \%$ & $18 \%$ & $73 \%$ \\
\hline India & $0.8(1980)$ & $0.7(2011)$ & $\$ 252$ & $66 \%$ & $34 \%$ & $0 \%$ \\
\hline South Africa & $2.8(2005)$ & $2.8(2005)$ & $\$ 162$ & $84 \%$ & $16 \%$ & $0 \%$ \\
\hline
\end{tabular}

\section{Quantitative Analysis}

Japan

Beginning with development indicators, Japan's development profile supports that it is a high income country. Japan's population of 127.1 million experienced a total fertility rate of -0.20 in 2014 . Negative population growth could be indicative of high disease burden, but Japan's life expectancy and literacy rate support that Japan is a high income country. Furthermore, life expectancy at birth was 83 total years in 2013, and adult total literacy rate for the percent of people ages 15 and above was $99.0 \%$. Compared to the other countries involved in this study, these are the highest life expectancy and literacy rates. Additionally, Japan's GDP in 2014 was $\$ 4.601$ trillion, but the annual GDP growth rate for that same year was zero. This GDP value is second only to China. Despite Japan's lack of economic growth, a 
zero GDP growth rate indicates that Japan has a stable economy. Given Japan's HDI index of 0.89 in 2013 , it is supported that Japan is a developed, high income country.

Continuing with TB population indicators, the relationship between Japan's high income and low communicable disease burden are readily observable. Each of the reported TB indicators is lowest in Japan compared to the other countries. The incidence of TB per 100,000 people in 2013 was 18 . This is including TB/HIV patients. Prevalence rate in thousands, still including TB/HIV patients, was 29 in 2013. Mortality in thousands was 2.1 in 2013, excluding TB/HIV patients. 64 Laboratory-confirmed RR-/MDRTB cases were reported in 2013. The number of patients started on MDR-TB treatment was unreported. Considering Japan is a high income country it is highly likely that every patient confirmed with MDR-TB was started on treatment. Overall, Japan's TB burden is low.

Lastly, Japan's health funding and resources for TB support that Japan has extensive support for TB patients. The earliest number of reported hospital beds per 1,000 people was 13.7 in 1980 . The most recent reported number of beds offers no observable change from this number at 13.7 beds per 1,000 people in 2009. Furthermore, the national TB program budget was $\$ 48$ million in 2014 . There must be a direct relationship between TB burden and national program budget, because Japan has the lowest burden and the lowest budget out of the five countries surveyed. The percent funded domestically, internationally, and unfunded for this amount went unreported. It can be estimated that nearly all of Japan’s \$48 million was funded domestically, considering Japan’s economic stability.

China

Starting with development indicators, China's development indicators support that it is an upper middle income country. China's population of 1.364 billion, the greatest population out of the five countries, experienced a growth rate of 0.50 in 2014 . Policies that limit the number of children allowed 
per family undoubtedly contributed to this rate. China's growth rate lies in between Japan's negative growth rate and the rate of the other countries. Life expectancy at birth was 75 total years in 2013, and adult total literacy rate for the percent of people ages 15 and above was $96.4 \%$. This is the third largest life expectancy, and the second highest literacy rate. Possessing a high literacy rate, and a low life expectancy, indicates that China has yet to epidemiologically transition. China's GDP supports this. In 2014 , China's GDP was $\$ 10.36$ trillion and the annual GDP growth rate for the same year $7.4 \%$. Out of the sampled countries, these values are both the highest values for the two indicators, and yet China's HDI index was 0.719 in 2013. Clearly China is an upper middle income country whose economic growth has outpaced its development. Because of this, it has yet to epidemiologically transition.

Continuing with TB population indicators, China proves to have a significant disease burden from TB. In 2013, the incidence of TB per 100,000 people was 70. This is including TB/HIV patients. Although this incidence value is second lowest, prevalence remains high. The prevalence rate in thousands, still including TB/HIV patients, was 1,300 in 2013. This is the second highest prevalence rate out of the five countries. Mortality in thousands, excluding TB/HIV patients, is also second highest at 41 in 2013. China is doing a good job controlling the spread of TB, but it is having difficulties treating. This is especially true for DR-TB. 4,183 laboratory-confirmed RR-/MDR-TB cases were reported in 2013. This value lies in the middle of the data set. However, only $52 \%$ of these cases received MDR-TB treatment. China has difficulty treating regular TB and DR-TB given the prevalence rate and percentage of treated DR-TB cases. Together these two qualities make China a high burden country.

China's high TB burden is understandable since it lacks health funding and resources for TB. The earliest number of reported hospital beds per 1,000 people was 2.2 in 1980 . This value increased slightly to 3.8 beds per 1,000 people in 2011. An increase in the number of beds is promising, but China still has problems with funding. Its national TB program budget was $\$ 347$ million in 2014 , which is the 
Johnson 29

greatest of the five countries. However, this value is only $81 \%$ of the budget required for a fully funded program. The percentage funded domestically and internationally was $78 \%$ and $3 \%$ respectively. $19 \%$ of the program went unfunded, a value second only to Vietnam. Considering the other three countries have a fully funded programs, this is concerning for China. Although China has space to care for patients, there is not enough money to pay for treatment. Cost is a barrier to treating DR-TB, so it is understandable that China has a high burden of DR-TB.

Vietnam

Vietnam's development indicators support that it is a lower middle income country. Vietnam's population of 90.73 million experienced a moderate 1.1 growth rate in 2014 . This is a median value compared to the other countries. Life expectancy at birth however was second greatest: 76 total years in 2013. The same is true for Vietnam's $94.5 \%$ literacy rate for people ages 15 and above. Vietnam's GDP in 2014 was lowest however at $\$ 186.2$ billion. This is accompanied by an annual GDP growth rate of $6.9 \%$ for the same year. This is a relatively high value compared to the other countries. It supports that Vietnam is a growing lower middle income country. Vietnam's HDI index was 0.638 in 2013 . As a country Vietnam is growing economically, but Vietnam only recently transitioned to lower middle income from low income.

Continuing with population indicators for TB, Vietnam's burden is nuanced, but it still confirms that Vietnam has yet to epidemiologically transition. The incidence per 100,000 people in 2013 was 144. This is including TB/HIV patients. It is a median value relative to the other countries. Prevalence rate in thousands, still including TB/HIV patients, was 190 in 2013. Mortality in thousands, excluding TB/HIV patients, was 17 in 2013. Both prevalence rate and mortality is the second lowest out the five countries. Overall, the TB burden is not high, but this changes when considering laboratory-confirmed RR-/MDR-TB 
cases in 2013. 1,204 cases were reported. This is a large number relative to the incidence, prevalence, and mortality. Perhaps Vietnam is programmatically successful with regular TB, but Vietnam lacks resources to deal with DR-TB. The percentage of patients started on MDR-TB treatment was 79\%. This covers a good portion of confirmed cases, but $79 \%$ is still not ideal.

Last, Vietnam's health funding and resources for TB provide potential evidence for its larger DRTB burden. The earliest number of reported hospital beds per 1,000 people was 3.5 in 1980 . The most recent reported beds per 1,000 people were 2 in 2010. This is the most significant decrease in the number of beds out of the five countries. It could be that Vietnam is losing resources, or that it has adjusted its healthcare system as it has recovered from significant historical events. Deficits are more understandable considering the National TB program budget. The total budget was \$73 million in 2014 . This is the second lowest budget in the data set. The percent funded domestically and internationally was $9 \%$ and $18 \%$ respectively, which leaves the greatest percent unfunded out of all the countries: $73 \%$. A high DR-TB burden is understandable in the context of such a high deficit.

India

India's development indicators supports that India is a lower middle income country. India's population is just behind China at 1.267 billion. However, its population growth rate is second greatest at $1.2 \%$ in 2014. This large, growing population has a low life expectancy at birth: 66 total years in 2013. This is the second lowest value in the data set. Adult total literacy rate for the percent of people ages 15 and above is the lowest at $71.2 \%$. Similarly, India's $\$ 2.067$ trillion GDP in 2014 is the lowest value in the data. The annual GDP growth rate for the same year is second highest at 7.3\%. India's $0.586 \mathrm{HDI}$ index in 2013 is lowest of all the countries. Taking all of this into account, India is newly transitioned from low income to lower middle income. It has yet to demographically transition. 
Continuing with TB population indicators, India has a greater burden than most countries. The incidence per 100,000 people in 2013 was 171, the third highest of the five countries. This is including TB/HIV patients. Prevalence rate in thousands, still including TB/HIV patients, was 2,600 in 2013 . This is the greatest prevalence in the data set. Mortality in thousands, excluding TB/HIV patients, is also greatest at 240 in 2013. Laboratory-confirmed RR-/MDR-TB cases in 2013 are significantly greater than any of the countries discussed thus far, but not greater than South Africa. 23,162 laboratory-confirmed RR-/MDR-TB cases were reported in 2013. The percentage of patients started on MDR-TB treatment was 91\%. Overall the burden is extreme relative to the other countries. This is not surprising since India's development indicators are the lowest. The burden of communicable disease is highest in those instances because countries have not epidemiologically and demographically transitioned.

Lastly, India's health funding and resources for TB provide more insight into its burden. The earliest number of reported hospital beds per 1,000 people was 0.8 in 1980 . This is the lowest value in the data set. It decreased to 0.7 beds per 1,000 people in 2011. Like a lower middle income country, India does not yet have all the resources it needs to match its health burdens. The national TB program budget was $\$ 252$ million in 2014. The percentage funded domestically, internationally, and unfunded for this total was $66 \%, 34 \%$, and $0 \%$ respectively. India relies on international funding more than any of the other countries. Altogether, India's burden warrants support from high income countries.

South Africa

Although South Africa is an upper middle income country, its development indicators are the most contradictory. South Africa's population of 54.00 million experienced a growth rate of 1.6 in 2014. This is the highest growth rate of all the countries. Even so, life expectancy at birth was lowest at 57 total years in 2013. High population growth rate and low life expectancy are stereotypical markers of a 
country that has not demographically transitioned after increasing its economic status. South Africa's level of education matches the shift towards higher income. Adult total literacy rate for the percent of people ages 15 and above was $94.3 \%$ in 2015. South Africa's GDP was the greatest of all the countries in 2014: $\$ 349.8$ billion. The annual GDP growth rate was relatively low for the same year at $4.6 \%$. South Africa's HDI index was 0.658 in 2013. This value lies in the middle of the five countries. Altogether, South Africa's economic growth has outpaced its demographic transition.

Continuing with population indicators for TB, South Africa has the greatest burden of all the countries. The incidence per 100,000 people in 2013 was 860 . This is including TB/HIV patients and far exceeds the value of any other country. Prevalence rate in thousands, still including TB/HIV patients, was 380 in 2013 . This is a median rate, but it is followed by a relatively low mortality rate. The mortality rate in thousands, excluding TB/HIV patients, was 25 in 2013. Numbers increase dramatically again for laboratory-confirmed RR-/MDR-TB cases in 2013: 26,023 cases were reported. The percentage of patients started on MDR-TB treatment was $41 \%$. These numbers are surprising for South Africa considering its economic standing as an upper middle income country. The only explanation is extreme economic inequality and zero epidemiological transition.

Last, South Africa's health funding and resources for TB prove that it has plenty of resources to alleviate its burden. The earliest number of reported hospital beds per 1,000 people was 2.8 in 2005 . This is also the most recent reported number of hospital beds. The lack of reporting can likely be attributed to instability throughout South Africa's history. Instability can have many negative impacts on health care systems. South Africa's national TB program budget is the median for the group. The National TB program budget was $\$ 162$ million in 2014 . $0 \%$ of this total went unfunded. The percentage funded domestically is largest in the data set at $84 \% .16 \%$ was funded internationally. It can be inferred 
that South Africa is fiscally independent, but perhaps not enough to effectively alleviate its communicable disease burden.

\section{Core Narrative Analysis}

Continuing below, core narratives (Appendix A) are analyzed for physician knowledge about global programs for TB. Secondary data is also discussed as necessary to explain parts of the core narratives. Core narrative analysis provides the main results for this research. A short description of the interview context is given before each analysis section. Both the core narratives and analysis of the core narratives reflects the order in which the interviews were completed.

Japan

$\underline{\text { Interview Context }}$

I met with two other physicians before meeting with the physician included in this study. Both were coworkers of the physician. One worked at the programmatic level and the other in a lab. I attempted to interview the first physician but he spoke too much about irrelevant information. His interview was discarded from this research. This was fine considering he was not a specialist in DR-TB. The second physician I met with worked in a lab. I did not interview him because I did not think he fit the subject description. I interviewed the third physician I met. He was a medical doctor in charge of the tuberculosis hospital. He worked in TB for 25 years and was in charge of the TB ward for seven or eight years. 


\section{Core Narrative Analysis}

In core narrative 4.1, the subject describes Japan's TB control program as independent from the Millennium Development Goals. He says it is "weakly influence by the global trend." As described in Table 1, Japan is the most developed out of the five countries. Its HDI is 0.89 . It also has the most hospitals beds per 1,000 people: 13.7 (Table 3). Japan also has the lowest burden of DR-TB at 64 laboratory-confirmed RR-/MDR-TB cases (Table 2). It makes sense that the goals do not necessarily influence Japan. But the physician continues to say that some physicians in the research institute are involved in the goals. He attributes this to their involvement in other countries. In core narrative 4.1, the physician states: "Some doctors were working in this research institute, of course involved in the Millennium Development Goal, especially for the technical assistance to Cambodia and Myanmar." It may be inferred from this statement that the physician believes that involvement in foreign TB control programs means a physician is involved in the MDGs. However, the physician does not think of himself this way. He states that he was involved in the prevalence survey in Cambodia, but then excludes himself from involvement in the goals with core narrative 4.1's complicating action. He states: "But the Millennium Development Goal, I wasn't really involved in the MDG."

Two concerns arise from the complicating action in core narrative 4.1. First, it is concerning that the physician should, by his own definition, be involved in the goals, but he still categorizes himself as separate from them. Doing a prevalence survey in another country directly contributes to MDG data. Perhaps this statement is culturally rooted. It could be that the physician did not want to take credit for something in which he was only partially involved. The physician could also have a different understanding of what it means to work for the MDG. He could think that he needs to play a central role in it in order to say that he contributed. Second, his resolution to this complicating action is to state that "Japanese TB control programs went on almost independently from the MDG." His reasoning for being uninvolved could be that Japan is independent from the goals. This implies that Japan is completely 
separate from the MDGs altogether, and that Japan can only be involved when helping other countries. Either way, both of these concerns imply that the physician does not think he is involved in the MDGs. It demonstrates that he knows about the goals, but it does not communicate that he understands them.

Moving on to core narrative 4.2, the physician does not answer the question. When asked about the Global Plan to Stop TB, the physician asks for clarification: "Pre-DOTs you mean?" He does not wait for an answer however, and continues to talk about global control. The complicating action is when the physician confirms he is talking about something else entirely. He states: "But now the Stop TB person says no more DOTs. New program activities. But there are some countries where DOTs is not implemented at yet." The resolution to this scenario is that "without the idea of DOTs I'm afraid the program will collapse completely." The Global Plan to Stop TB does not involve the elimination of DOTs. It plans to enhance and expand DOTs (World Health Organization 2010). There are two potential reasons the physician responded this way. Either the physician did not know what the plan was and he did not want to admit it, or he simply misunderstood. I do not correct him when he begins talking about PreDOTs, but he does not ask for clarification either. This does not mean he does not know Stop TB, but it does not provide evidence to show he is knowledgeable about Stop TB. Still, it is concerning that he did not accurately recognize the name.

Continuing on with core narrative 4.3 , the physician provides reasons for his separateness from the MDGs by separating his work from Japan's own national TB program. The physician states that he works in a national TB program "only ten percent of my time. Part because most of my work is clinical work." This implies separation between himself and the programmatic level, because he mostly works with patients. While this is so, he communicates that he is a member of the national advisory group for public health. According to him, this is still not enough for him to be a full part of the program. The complicating action is that the physician merely provides data to influence policy. Resolution only happens because "for that kind of research I am sometimes involved." Perhaps the physician thinks 
himself uninvolved because of his culture. Maybe he does not think that his individual actions are important. He could believe there are others who are more involved that should get credit. Or he does not think he is important as an individual. It is difficult to tell. Either way he does not categorize his clinical work as programmatically significant.

In core narrative 4.4 , the physician repeats the point in core narrative 4.3 and does not give a sufficient response. When asked if he knows his countries goals for TB he says: "My contributions will be very small." He goes on to discuss how he is not a policy maker. Also, he says that Japan's Ministry of Health and Welfare and Labour is not like the CDC. The complicating action is that "in Japan, within the ministry there is no specialist." The resolution is nearly the same as core narrative 4.3's where the physician says he provides data to the policy makers. While this was an acceptable explanation for core narrative 4.3 , core narrative 4.4 requires the physician to communicate specific statistics included in the MDGs. It is possible that the physician does not know his country's goals and that he is unwilling to admit it. Out of all the interviewees, he is the only one that did not provide specific statistics in response to the question.

Moving on to core narrative 4.5 , the physician indirectly answers that not all cases of DR-TB can be treated. He states that cases can be treated "in one sense clinically," and that he treats many cases. The complicating action is an indirect statement on whether all cases are effectively treated: "Sometimes we fail, sometimes we succeed." Before the difficult cases of tuberculosis "there are many cases who are usual MDR." The resolution is that MDR cases "can be treated not in a specialized hospital, but in other hospitals." This is not the ideal resolution, but it is expected. Not all XDR-TB cases can be effectively treated. While the physician admits that sometimes he fails, he does not focus on the main question at hand: drug-resistant cases that cannot be treated. Cultural perceptions of failure and willingness to discuss failure could be the reason for this response. Or the physician may not want to admit the realities of XDR-TB. 64 cases of laboratory-confirmed RR-/MDR-TB cases were reported in 
Japan (Table 1). The number of patients started on treatment is unreported. Perhaps his answer reflects the unreported data. Japan may want other countries to assume it is successful with all cases.

Continuing with core narrative 4.6, the physician's responses reveal negative thoughts toward the interviewer. The goal of core narrative 4.6 was to establish whether the physician has access to bedaquiline. He responds on his own terms by stating that he has access to delamanid. Then he continues to share that bedaquiline is in phase two clinical trials. It will be available in three or four years. The complicating actions are that Capreomycin is unavailable, that Janssen Pharmaceutical Company is not interested in Japan because it is a small market, and that he needs to know whether bedaquiline and delamanid can be used together. NIH studies in the US, and interest in another drug, resolve the complication: "If other institute is doing the same study we probably cannot compete." I issue a follow up question, asking if bedaquiline will be essential for future treatment. In my question I imply that it will be essential to XDR. The physician responds: "Definitely no. But it will play essential role for treatment of XDR." He goes on to explain the acronym for XDR, how essential bedaquiline will be, and that it will not be used for regular TB. It is my perspective that the physician should have known that I already knew this information, based on the fact that I knew about bedaquiline. His response makes me think that he wanted to devalue my knowledge base, or that he did not want to recognize that I came in with prior knowledge.

Several explanations can describe the interviewer's negative response in core narrative 4.6. The physician could have legitimately thought I did not understand bedaquiline, or he may have wanted to uphold a power dynamic since he was superior as the professional. I am unfamiliar with the exact cultural dynamics at work, so I cannot know his perspective completely. It seems unlikely that he would think I was completely ignorant for reasons I already stated. Therefore, I would like to rule out that he genuinely thought I did not know anything about bedaquiline. Leading up to that point he already avoided many of my questions. He could have been frustrated and felt the need to reclaim social power. 
This could be caused by the professional distance between us; I was his younger. Whatever the reason, his response casts a negative light on the interview.

Core narrative 4.7 supports this thought when the physician asks why I interview him at all. The narrative series concludes with core narrative 4.7, which seeks to answer whether the interviewee has any more information he would like to share. To orient the narrative, the physician asks if I know where TB and MDR-TB are most prevalent. He explains that the US and Japan are both supporting other countries' TB burdens. The complicating action is that Japan's burden is so small. His resolution is to ask: "I'm sorry. Ah. So I wonder why you are interested in them, global TB for the global programs?" The physician proceeds to laugh. By framing the narrative in this way the physician asks why I am bothering to do research in Japan. This is a critique of my decision to interview him.

I respond to this critique in core narrative 4.8 , prompting an additional core narrative. I frame the question by explaining the intensive treatment for MDR-TB and XDR-TB, and my concern with the barrier that cost effective analysis creates for DR-TB cases. The physician explains that regular TB is cheap to treat, that MDR-TB is expensive, and that when any patient is cured treatment ends. Then he explains that he thought treatment was cost effective since he started working with TB. This confirms that the physician has high self-esteem. The complication, however, is beyond his immediate control: "But after the year 2000 when the WHO more focuses on MDR-TB and the private sector and I was afraid we cannot continue because of its high cost." The WHO and the private sector complicate his work. The Gate's Foundation and the Global Fund have helped resolve this complication. Still he says the Global Fund will run out soon and that the "activities of global fund might have spoiled some persons. Spoiled means that we might not be able to continue what could be done." And so the physician's final narrative contradicts the questions he had for my research, much like his previous statements. He admits that DR-TB needs global support despite the fact that he questioned my interest in Japan. 
Overall, the physician in Japan was not knowledgeable about global programs for TB. He mentioned that global TB control started in 1994, but he did not describe the MDGs or Stop TB. When asked about Stop TB, he discussed an unknown movement called Pre-Dots. This movement is not mentioned in any literature involved in this research. As far as the researcher is aware, no one is trying to end DOTs. Despite his research contributions to Japan's national TB program, the physician described himself as uninvolved in the MDG. Furthermore, the physician did not admit that some forms of DR-TB cannot be successfully treated. He mentioned that he had access to delamanid, that he was conducting clinical trials with bedaquiline, and that it was problematic that capreomycin was not available. He blamed delayed access to bedaquiline on Janssen Pharmaceutical Company. Lastly, he expressed worry that global funding was running out.

China

Interview Context

The physician I met with was the director of the Infectious Disease Department for the hospital where he worked. He worked at the hospital for more than twenty years, and worked in TB for 15 years. He was also a member of the Society of Tuberculosis in China. The physician was late by an hour to our meeting. This was understandable because he was tending to a patient. During the interview the physician received several phone calls. When we completed the interview he gifted me a book about TB.

\section{Core Narrative Analysis}

In core narrative 5.1, the subject does not hesitate to say he is familiar with the MDGs, but he is unsure whether China can meet the goals. He says yes multiple times in response to hearing about the goals. This implies confidence. He also states that they are effective. However, the complicating action makes him seem less certain. The physician states: "Sometimes it is difficult to do according to this 
project around the world. I think sometimes it is very difficult to do TB treatment in very remote countryside." China has a population of 1.364 billion, the greatest out of the five countries, but it also has the largest GDP with the largest growth rate: $\$ 10.36$ trillion at $7.4 \%$. While this is so, China has the second largest prevalence rate: 1,300,000 cases, including HIV and TB. It is understandable that the physician is initially confident, but still concerned about reaching everyone in the population. He adds that MDR-TB control is difficult. The numbers support that $52 \%$ of the 4,183 laboratory-confirmed RR/MDR-TB cases were started on treatment. In resolution, he says he is unsure whether China can get the goal or not. Switching from confidence to uncertainty is confusing, but at the very least the physician communicates that he knows about the goals and China's general status in relation to the goals.

In core narrative 5.2, the physician communicates similar confidence and doubt about China's progress. He confidently states that he has heard of Stop TB, and that he thinks it effective. However, doubt is implied by the complicating action when he says: "If we do it will be effective." This statement means there is possibility that China will not reach its goals for Stop TB. Next he explains why he is both confident and doubtful: "I think the project it have some reputations for the diagnosis for MDR-TB detection and directly observed treatment. I think that directly observed treatment also for MDR-TB it works." He believes there are some qualities to the plan that have been helpful, but as stated before, only $52 \%$ of cases were started on MDR-TB treatment in China.

Continuing on to core narrative 5.3, the physician explains why DR-TB makes it difficult to achieve the MDGs and Stop TB. Describing China's national TB program, the physician says: "In China we have a very strong network of TB." He explains that the CDC is heavily involved in the national program. Everything is reported to the CDC. With the CDC's help much of TB treatment is given for free. Perhaps this represents the $3 \%$ of China's internationally funded budget (Table 2 ). Also, the physician shares that China has been given access to new detection techniques and published some papers on molecular detection. Participating in research is positive. It means that China is not so inundated with patients that 
it cannot analyze treatment methods. However, the complicating action is that "for just strains from all over China they found that ten percent of the patients MDR-TB. In all MDR-TB patient ten percent are XDR-TB. That means almost one percent of the TB patient are XDR-TB." This complicating action has a poor resolution. The physician says that these cases require either a new drug that is difficult to get, or that the new drugs are extremely expensive. $19 \%$ of China's National TB program budget is unfunded. It makes sense that the physician is concerned with the cost of the drugs.

In core narrative 5.4 , the physician is able to describe China's goals for TB. The physician confidently says that China has the goals. He shares: "Basically China's incidence is now in the middle, around 1,005." He also mentions mortality offhand. According to Table 2, the incidence of TB (including TB/HIV patients) per 100,000 people is 70 . This value cannot be correct. It could be that the doctor meant to say prevalence rate. The prevalence rate in thousands, including HIV and TB patients, is $1,300$. This is much closer to the value he communicated. If there was misunderstanding with word choice, it is possible that miscommunication occurred several times in core narrative 5.4. Regardless, the physician demonstrates that he knows several things about the MDGs and Stop TB. Repeating the shorthand name "Stop TB" supports that the physician is familiar with the plan. It is also promising that he knows both plans end in 2015. He continues to explain incidence is a major problem, but that China has made it decline over the last several years because "we have best job ever of TB control." The complicating action is the rise of MDR-TB. He shares that it is being resolved by a steady decrease in incidence. A more thorough answer would include specific statistical values about incidence and treatment success rates, but communicating prevalence/incidence, and mortality, supports that the physician is aware of the terminology involved in the MDGs and Stop TB. Mentioning these indicators reflects the 2005 reporting change outlined in Stop TB.

Moving on to core narrative 5.5, the physician implies competition between China and the United States. When asked if he can effectively treat all DR-TB cases, he says: "Sure. Now we just take 
the community center drugs. Some effective first you add drug cures MDR-TB most of the time the strains are resistant to most." This is not a direct answer. Not all DR-TB cases can be effectively treated. He explains that recently China has been able to access all the same drugs used in the United States. The complicating action is the United States recently issued a new drug. The action remains unresolved since China does not have access to the same drug. It is interesting that the physician would initially describe China's situation as similar to the United States when he contradicted that statement with new information. This could be an incorrect assumption to make, but it seems like the physician wants China to be equal with the United States. There is a clear hierarchy when one country has access to drugs that the other cannot access. It can mean life or death for some patients. It is counterintuitive that the physician does not draw attention to this issue especially when the United States is involved in TB control programs in China. He could ask for access to the same drug, but distribution is a complicated process. I am not sure how to explain this response.

When asked about bedaquiline in core narrative 5.6, the physician describes barriers to accessing drugs. He acknowledges my knowledge base as the interviewer by assuming that I know about bedaquiline. The complicating action of core narrative 5.6 is that bedaquiline may be unsafe. It has not passed. Reasons why bedaquiline may not have passed include severe side effects or negative interactions with other drugs (Monedero 2016). Either of these situations may have made Chinese officials wary of the drug. The physician also mentions that the price is very expensive. His resolution is to test new drugs: "with which I could this year, August here have access to these new drugs." A lengthy amount of time passed before bedaquiline became a consideration for DR-TB treatment. It is unknown to which drug the physician was referring, or how long it would it would take until it was approved. Janssen Pharmaceutical Company is also mentioned for its involvement. The reference is neutral. Altogether, these core narratives illustrate vague knowledge about global programs for TB. The physician verbally confirmed he knew about the MDGs and the challenges of administering DOTs care in 
rural settings. He said that Stop TB had a reputation for improving MDR-TB detection and treatment methods. In terms of China's national TB program, he was able to describe the CDC's general involvement. However, he miscommunicated China's goals. Out of the incidence, prevalence, and mortality rates associated with global goals, he only reported a value for incidence and briefly mentioned mortality. The incidence rate he communicated did not match China's statistical profile. It is likely that he meant to say prevalence. In regards to treatment, the physician did not admit that some DR-TB cases cannot be successfully treated. He said that bedaquiline, although controversial, was finishing clinical trials. In conclusion, he mentions that some new drugs are awaiting clinical trials throughout the world.

Vietnam

$\underline{\text { Interview Context }}$

The physician I met with was a doctor in a TB and Lung Disease Hospital. She worked in medicine for about 22 years. During her time at the hospital she occupied many different positions. First she worked in a lab. Then she moved to planning general public. After that she was moved to the outpatient department where she worked at the time of the interview.

We met in an office that was operated by a foreign country. The physician was accompanied by a coworker. I think this was because she was not confident with English. When I asked if the coworker could leave, he left willingly. The physician kept a sheet of statistics nearby during the whole interview. She referred to the data frequently.

\section{Core Narrative Analysis}

In core narrative 6.1, the physician's minimal response communicates sufficient information about the MDGs. She says that she has heard of the MDGs and thinks they are effective. However, the 
complicating action is that the goals are not directly impactful. Her resolution to this complication is to say: "I think it impacts our country." Rather than choosing to state that the goals are generally effective, the physician is able to distinguish layers to Vietnam's programmatic efforts.

Similarly, in core narrative 6.2 , the physician has a unique view that provides useful information about Vietnam's relationship with Stop TB. The physician admits that although she has heard about Stop TB, she does not remember the exact details about the plan. Despite not remembering the specifics, she thinks Vietnam can complete the plan. The complicating action is for the physician is that she does not "work in the TB management program directly. So I just work with TB patients." Here she draws a distinction between the roles of program manager and clinical physician. It is useful to know that she considers the two roles separate from one another. However, she counters this by saying: "sometimes the policies we can know and follow in practice." This is an important distinction made by the physician. Even if a physician is not directly involved in making programmatic decisions, they can still be informed about national progress.

Continuing with core narrative 6.3, the physician demonstrates she has extensive knowledge about Vietnam's national TB program. She begins by describing the different levels of communication. The main TB headquarters are in Hanoi. There is a TB and lung disease hospital, and a TB center/unit, in each province. Data is sent from each district TB unit to the district TB center, which is then sent to the main TB headquarters. Community networks are below the TB unit. She explains that the first two months of treatment occur in the district TB unit. From there drugs can be administered in the community. The complicating action of this network is that patients need to start treatment at the TB office in their province, rather than the medical office in their community. The resolution is that the centers are usually very close to people's homes: "we perform DOTs for all TB patients in my country." The data supports that this is a highly organized system. Although Vietnam's incidence is the median for the data set at 144 cases per 100,000 people, prevalence and mortality are second lowest at 190,000 
cases and 41,000 deaths (including HIV and TB). 79\% of the 1,204 laboratory-confirmed RR-/MDR-TB cases were started on treatment. Considering that $73 \%$ of Vietnam's National TB program budget went unfunded, and the number of hospital beds decreased from 3.5 in 1980 to 2 in 2010, it is clear that resource abundance is not the reason for Vietnam's success.

Core narrative 6.4 provides specific evidence for the physician's knowledge about global programs for TB. When asked if she knows her country's goals for TB, the physician replies yes. However, the complicating action is that the physician recites the outdated 70/85\% rates: "We can cure the patients more than $85 \%$." She goes on to say: "We finished it. This is from my city." In the physician's mind this is sufficient information to completely answer the question, but it does prompt further discussion. 70/85\% values were eliminated from Stop TB documents in 2005. Those values represent indicators that are out of date. The physician did not explain further, but this evidence shows that the physician did not know that a reporting change was made in global plans for TB. Perhaps her city measured progress differently than Vietnam as a whole, but it would be easier for the country to share the same goals.

In core narrative 6.5 , it is apparent that there are limitations to the physician's knowledge about DR-TB. When asked if she was able to effectively treat all DR-TB cases, the physician says: "Yea. In my hospital we have a department for MDR-TB." It is unclear whether the physician meant that all cases could be effectively treated, or that all cases could be started on treatment. She may have simply reported whether cases are treated without considering treatment efficacy. Either way, she explains that there is protocol for DR-TB treatment. Specialists administer treatment until the patient can be referred back to a regular TB unit. The complicating action of this narrative is that the physician does not know the drugs used in DR-TB units. She does not know the drugs because it is not her job to take care of DR-TB patients. It is outside her immediate influence. The resolution is that drugs are supplied to each TB unit where the patient can continue treatment when they have significantly recovered from DR-TB. 
Although she is not a DR-TB specialist, the physician demonstrates she is knowledgeable about programmatic efforts to alleviate DR-TB.

Narrative 6.6 concludes narrative series for the physician in Vietnam, and confirms that bedaquiline is unavailable. The physician reiterates that she is not a DR-TB physician, but that she does know some second line drugs. Regarding bedaquiline, she says: "That drug is not available in my city." Knowing this means there must be some conversation happening in Vietnam about the drug. The complicating action is that she does not know when it will arrive. She resolves this complication by stating: "I can refer them to the MDR program and other doctor can take care of them."

All in all, the physician in Vietnam was not very knowledgeable about global programs for TB. She provides few details about the MDGs, describing them as impactful on the country as a whole. In regards to Stop TB, she had heard about it but did not remember it in detail. She thought she could know and follow the policies in practice. Alternatively, the physician was familiar with Vietnam's national TB program. She described the country level, provincial level, and local level in depth. As far as Vietnam's goals, she mentioned the $85 \%$ cure rate, which is out of date. Additionally, the physician did not mention that not all DR-TB cases can be effectively treated. In the end, she was able to confirm that bedaquiline was not available in her city.

India

Interview Context

The physician I interviewed was a TB consultant for his state. He had been working in TB control programs for 17 years. In 2003, he became key personnel in programmatic planning and then in 2010 he became the district head as a consultant. When I found the physician's office he was waiting in a room that I was able to walk in to without anyone asking questions. Nobody was monitoring the building or 
checking people in. Furthermore, the building we met in was next to some very old buildings that I was told would be torn down soon. They looked like ruins.

At first, when I tried asking the physician my questions he could not understand what I was saying. I had to give him the paper with my questions written out. After he finished answering a question, I directed him to the next question by pointing to the question on the paper.

\section{Core Narrative Analysis}

In core narrative 7.1, the subject proves that he is highly knowledgeable about the MDGs. When asked if he knows about the goals, he states yes. He explains: "Millennium Development Goals have been framed during our TB training of the TB control program. As program manager we have all been coordinating several program roles standardized by the Millennium Development Goals. DOTs." He continues to explain that India is not achieving all the goals, but still they are trying to achieve the "development goals." Using such direct and specific word choice leaves no reason to doubt his knowledge.

In core narrative 7.2 , the physician also supplies evidence to support that he is knowledgeable about Stop TB. He explains that the Stop TB was implemented in his training program as program manager: "We would talk about various funding agencies for this TB control program, especially over here. So these programs are all being conducted with the help of international funding agencies. As part of that we have been hearing information about this." When asked if Stop TB is effective he says of course it is: "because of the impact of giving for Stop TB control program." He implies that Stop TB is useful because of the financial support it garners from the global community. The impact of international money is supported by the data in Table 3. Of India's $\$ 252$ million budget, $34 \%$ of it is funded internationally. This is the largest percent of international funding out of the five countries. The complicating action in the Stop TB narrative only arises if the funding is theoretically unavailable. 
Because it is available, the resolution to this narrative is that physicians are in "a good position to go to the place with those people who are in need of TB service." India's population is the second largest at 1.267 billion. It has lowest HDI of all the countries: $0.586 \mathrm{HDI}$. It makes sense that this would be concerning to the physician.

Continuing on to core narrative 7.3 , the physician describes highly unique and involved national TB program. When asked if he works in a national TB program, the physician answers yes. Describing how that program functions, he states that training is provided to many different groups: medical officers, primary leaders, lab technicians, the general public, and NGOs. Out of all the countries, this is most extensive list of individuals involved in the national program. The complicating action of an extensive program is that it "covers almost all of India." The resolution however is that "every government hospital from medical college to primary health center all are following the state guidelines as described in the revised TB national control program." Considering India's TB burden, it seems that this kind of method is imperative for success. India has the second highest incidence at 171,000 cases, the greatest prevalence rate at 2,600,000 cases, and the greatest mortality rate at 240,000 deaths. These numbers are intimidating, especially when the number of laboratory-confirmed RR-/MDR-TB cases is 23,162 . However, focusing on the social aspects of disease has produced success: $91 \%$ of those patients were started on MDR-TB treatment. Clearly the national program is successful, and the physician is knowledgeable about it.

In core narrative 7.4 , the physician confirms he knows the old 70/80\% markers. He states: "Yes. The ultimate goal is to have a TB free India. And initially we set two objectives for achieving this goal." He continues to explain that the goals were to achieve a cure rate of $85 \%$ and a detection rate of $70 \%$. The resolution is that the physician continues to discuss how India is almost consistently achieving the out of date goals for a year. Providing specific statistical values reinforces the physician's knowledge about the goals. However, these values are still out of date. The physician does not mention incidence, 
prevalence, or mortality rates to reflect the 2005 reporting changes. This suggests he is not up to date on global programs for TB, despite working in an effective program.

Core narrative 7.5 is longer and more complicated when the physician discusses DR-TB. The physician says that he is able to effectively treat all cases of DR-TB. However, this is contradicted by information he provides later. He shares that with the establishment of a working DR-TB program, each of India's states quickly adopted the control program. In that statewide program, 163 MDR-TB cases were detected and 140 put on treatment. The 23 person difference resulted from those 23 individuals being sent to their respective districts after they were diagnosed. The complicating action shows that there are barriers to treatment, besides access to medications. Of those 163 patients: "Seven died before starting treatment because we were using slow culture. It would take two to three months to get their results unfortunately." Additionally six people refused treatment because they were "fed up with primary drugs." The resolution involves more efficient technology for earlier detection and earlier treatment, namely from line probe assay. Furthermore, of the 61 patients started on treatment since 2008, 61 have been cured. One patient was identified as XDR-TB and put on the relevant treatment. Communicating exact patient statistics indicates that the physician is knowledgeable programmatic efforts at the local level.

Continuing with core narrative 7.6 the physician shares that DR-TB patients are given social support to improve treatment outcomes. He admits that bedaquiline is not available yet. Not even in private hospitals. The complicating action is that bedaquiline is not "permitted to sell for safety reasons. Most of them will not be able to go for delamanid because of severe side effects. And many of them are literally poor." The resolution to such poor circumstances is to provide DR-TB patients with nutritional supplements when they come in for treatment. This program is new however: "We are successfully implementing it since the last four months. It's going on well." 
Core narrative 7.7 provides insight to the physician's personality. When asked if he has any more information he would like to share the physician orients his narrative by stating: "We are optimistic. We hope we will be able to overcome this problem one day." The complicating action is that this may not occur in his life. His resolution withstands the odds: "But we are optimistic."

Relating the core narratives to India's quantitative profile, the physician is generally knowledgeable about global programs for TB. The physician knew both the MDGs and the application of DOTs. He also knew about Stop TB, specifically referring to the financial support it offers. Furthermore, the physician described his national TB program in depth. He discussed the involvement of medical officers, primary leaders, lab technicians, the general public, NGOs, and celebrities. Unfortunately, the physician reported the $70 / 85 \%$ Stop TB indicators. He did not mention incidence, prevalence, and mortality, although the physician communicated detailed information about the DR-TB patients in his program. Unfortunately, he did not have access to bedaquiline, nor delamanid due to its severe side effects.

South Africa $\underline{\text { Interview Context }}$

The physician I interviewed in South Africa was a DR-TB doctor employed by an NGO. She had been in her position for five years. Before that she was responsible for TB patients in a hospital for two years. The physician was a British expat working in South Africa. She was used to interviews because part of her job description involved outreach for TB.

I spent the day with the physician in South Africa. She picked me up in her car on the way to work because she worked some distance from where I was staying. I think many of her responses were lengthier because I spent the day with her. Also, we shared the same first language. 


\section{Core Narrative Analysis}

In core narrative 8.1 the subject describes the MDGs as inconsequential. She confirms that she has heard of the MDGs, but the language she uses to describe their effectiveness is less certain. She says: "I guess in a way. I suppose you know the goal to reduce new TB infections and deaths from TB does impact our work a little." The complicating action is that people are generally aiming towards the goals anyways, and the resolution is that people work towards the goals whether they exist or not. She adds: "I'm not sure it influences the local level." This is the only instance that the physician described the goals as inconsequential.

Alternatively, in core narrative 8.2, the physician finds some positive correlations with Stop TB. When asked if she has heard of Stop TB, she confirms that she has heard of it. Stop TB has indirectly raised awareness and increased funding, research, and development: "I guess it's helped." Still her work is not a result of the goals. It is merely reflected in them: "We're committed to fighting TB so we have all sorts of different interactions with different stakeholders so we would support all those kinds of initiatives. And that's reflected in global programs." The narrative's complicating action arises when the physician describes South Africa as "middle to low income." According to World Bank, South Africa is an upper middle income country. It has a significantly smaller population of 54 million, the smallest of the five countries, and the second lowest GDP at $\$ 349.8$ billion. South Africa has a $0.658 \mathrm{HDI}$ which is the median index for the group. In theory, South Africa should need less support from external entities. The fact that $84 \%$ of its national TB program budget is domestically funded supports this. The resolution to this conflict is that South Africa's burden is great enough that it can still benefit from the plan. As mentioned before, South Africa has the greatest number of DR-TB cases. It is still benefits from additional help: "Rolling out gene Xpert, rolling out rapid diagnostics, you know access to the new drug bedaquiline, that's probably because of this raised awareness and commitment to working with TB." The physician attributes technological innovation to efforts in the global community, but not local success. 
Core narrative 8.3 supports that the physician is thoroughly knowledgeable about South Africa's national TB program. In core narrative 8.3, the physician illustrates the intersection between private and public entities. Although she does not consider herself directly a part of the national TB program in South Africa, the physician says: "our project is very integrated with the department of health structure." Her NGO is involved with developing programs that are taken over by the department of health. Doctors in primary healthcare clinics, TB nurses, district level department of health managers, provincial department of health managers, specialists in other clinics, doctors that run TB hospitals, and national department of health managers are just some of the people she collaborates with in her line of work. It is clear the physician is knowledgeable about the national TB program because she is able to list each management level, and the interactions she has with each level. The complicating action of a multilevel system is that everyone must have a "good working relationship with the department of health at the local level and the national level." The resolution to core narrative 8.3 is that "different partners from across South Africa, the department of health but also some NGOs" are all working to improve access to bedaquiline.

Moving on to core narrative 8.4, the physician provides dated information about South Africa's goals for TB. When asked if she knows the goals, the physician initially expresses doubt. She says she does not know them "off the top of my head." While this is so, she is able to name the $70 / 85 \%$ indicators. However, this is the complicating action because it is insufficient evidence. These markers were removed from official TB documents in 2005. The resolution is that the physician does not know anything more specific than that; she does not think other physicians are informed either.

To relate the narrative to other physicians in South Africa, I asked whether the physician thought other physicians knew the goals. She said she doubted it. Several lines of reasoning could explain this response. First, the physician could think highly of herself and poorly of her local counterparts. She possessed a job generally admired. But she could also be thoroughly knowledgeable 
by nature of being a physician that has chosen to work in a country with greater TB burden than her own. An individual that has chosen to do this is likely more aware of global issues. They probably also have an innate interest in staying informed. If the physicians she worked with did not need her, they would likely be informed about global conversations already. They would also know how to utilize them and they would not ask her to work with them. The likely explanation is that South Africa's burden is overwhelming, and private support is helpful.

Continuing with core narrative 8.5 , the physician explains DR-TB treatment. When asked if she is able to effectively treat all DR-TB cases, the physician replies: "No. Nobody is." No other physician admitted this. She continues to explain that diagnosis is the first difficulty, followed by getting patients on treatment. Clearly her work has brought success: “90\% of our patients who are diagnosed on to treatment... compared to the rest of South Africa which is around 50\%." This statement is supported by the data in Table 3: $41 \%$ of patients are started on MDR-TB treatment. She goes on to explain the technology that has helped with detection and treatment. She has access to smear microscopy, culture, drug sensitivity testing using culture based phenotypic conventional drug sensitivity testing, line probe assay, and a university laboratory for cases that demonstrate genotypic discordance. While this is so, the complicating action is that the current standard MDR regiment only has a $50 \%$ success rate. Also, new technology is being implemented slowly. At the time of the interview, line probe assay had not been routinized. These complications leave one resolution: "to decentralize care to give that same treatment but to more people." That is until new drugs are developed. The physician said she was involved in this process.

In core narrative 8.6, the physician speaks about bedaquiline. She shares that South Africa has access to bedaquiline and conducted most clinical trials for the drug. A bedaquiline access program started in 2013, and from there its availability expanded. The complicating action is getting bedaquiline to all the TB hospitals in the country. She explains the resolution is that she is helping expand access at 
the provincial level. Accessing bedaquiline early was "lucky" for South Africa. This is the most detailed explanation for bedaquiline. South Africa is also the only country to roll out access on such a large scale. At this point, I share with the physician that Japan is the only country involved in my study that has been able to access the drug. She explains that a lot of the clinical trials were run in South Africa, which is the main way people access the drug. In her specific situation, patients accessed bedaquiline through an expanded access program. Larger registration followed this across the country because the department of health wanted to expand its use.

After the main core narratives, two narratives followed concerning drug companies. In the question for core narrative 8.7, I ask if the interviewee has any more information she would like to share. She points out that I should be concerned about delamanid. Delamanid is more difficult to access. Otsuka, the company in charge of it, is willing to give the drug if countries apply for their compassionate use programs. The complicating action is that Otsuka is creating barriers to delamanid: "They have such stringent confidentiality controls on their protocol it means that a lot of countries can't access it because within their local regulations you know they can't get over those requirements." A further complicating action is that Otsuka will complete clinical trials, register a drug in a country, and then make delamanid inaccessible to patients that were involved in their clinical trials. Instead, those people must go through the compassionate use programs which involve a lengthy approval process. The physician says the only resolution to this issue is to focus on the problem more. This statement is general and does not indicate that the physician has a plan to address it. However, she is clearly aware of the larger conversations with the drug companies. She communicates extensive knowledge about treatment access.

Lastly, I pose a second follow up question that produces core narrative 8.8. I ask the physician who controls bedaquiline and delamanid, and where the drug companies are based. She says that the drug companies control the drugs. Otsuka is based in Japan and Janssen is somewhere in Europe. Expanding on bedaquiline, she shares that the drug has already been registered, and that "once a 
country registers a drug then the use is really not dependent on Janssen." However, the complicating action to this narrative stems from Otsuka and delamanid: "Because it's not yet been registered they want to control its use." The resolution is not really a resolution at all: "They're really the ones who are you know effecting delamanid." Until this interview no other physician mentioned issues with drug companies. Perhaps the expat is more willing to voice her concerns because she is a part of an NGO that has already proven itself to the global community. Additionally, she comes from a country that is used to recognition from the global community.

Altogether, the physician in South Africa communicated vague information about global programs for TB. She was neutral towards the MDGs, saying that people generally aimed towards the goals whether they existed or not. At the local level, she said she was not sure they were influential. Regarding Stop TB, the physician said the program helped raise awareness, and improved access to new drugs and diagnostics. In addition to this, the physician was able to describe the national TB program in South Africa. Although she said she did not work in one directly, she demonstrated that her work was intertwined with South Africa's program by describing her involvement in the local, provincial, and national levels. As far as South Africa's goals for TB, the physician communicated the out of date $70 / 85 \%$ rates. Notably, the physician admitted that not all cases of DR-TB could be effectively treated. She was able to start $90 \%$ of her patients on treatment, but treatment was only successful $50 \%$ of the time. Additionally, the physician provided details about the drug access. She explained the benefits of clinical trials and the regulations that prevent patients from accessing new medications after drugs have been registered. Delamanid was mentioned as an important new drug that should have been addressed in this research. The physician said Otsuka, the company that controlled the drug, made stringent confidentiality laws that many countries could not follow. Patients that were being treated with Delamanid through compassionate care programs could no longer access it after it was registered. Lastly, the physician explained that Otsuka is based in Japan and Janssen was based in Europe. 


\section{Chapter 5: Conclusion}

There are many different ways to analyze the data involved in this research. The focus of this study is purely what physicians know about global programs for TB. As such, results related to this topic comprise the main results of this study. Areas for future research are discussed intermittently. Although the results obtained in this research are not generalizable, they highlight important interactions between individuals and programs that can help inform global programs for TB.

\section{Physician Knowledge}

Altogether, two common themes bring to question the effectiveness of global programs for TB: physician knowledge and goal achievement. Commonly physician's knowledge about global programs was dated. An example of how physicians were uninformed includes frequent mention of $70 / 85 \%$ rates. $70 \%$ case detection rate and $85 \%$ treatment success were removed from the reports in 2005 (World Health Organization 2010). The 2015 Global Tuberculosis Report has no mention of either statistical value. $70 / 85 \%$ values were replaced with seventeen targets measured against the total number of cases diagnosed, notified, and treated in DOTS programs (World Health Organization 2010). Of the seventeen targets, two indicators are relevant for the current research: $100 \%$ percent of laboratory confirmed MDR-TB cases started on treatment and greater than $75 \%$ treatment success rate for laboratory confirmed MDR-TB cases (World Health Organization 2010). None of the countries involved in this research met either of these goals. Effectiveness of the MDGs and Stop TB is questionable for both miscommunicated indicators and failure to meet the goals for DR-TB. Considering this, whose fault is it that physicians are not informed?

Physician knowledge varied from doctor to doctor. The physician in Japan offered the least knowledge about global programs for TB. He did not describe his country's goals, relevant indicators, or 
Japan's national TB program. The physician in China verbally confirmed he knew about global programs, but provided vague evidence to support his assertion. He described China's incidence and mentioned mortality, but the statistical value he used did not match the secondary data. Choosing to report incidence and mortality was still promising, because it reflects the 2005 reporting change. The physician in Vietnam heard about the MDGs and Stop TB, but she could not describe them thoroughly. She said $85 \%$ of patients were cured, which was consistent with the pre-2005 statistical markers. Despite reporting the wrong statistic, she provided a complete description of Vietnam's national TB program. The physician in India knew many details about the MDGs, Stop TB, and India's national TB program. However, when asked about his country's goals, he cited the 70/85\% rates. The physician in South Africa shared the same knowledge base, but also cited the $70 / 85 \%$ rates.

In the process of communicating their knowledge, many of the physicians described their underlying views toward global programs. For instance, many of the physicians described themselves as separate from the goals. In core narrative 4.1, the physician in Japan directly stated: "I wasn't involved in the MDG." In core narrative 6.2, the physician in Vietnam said: "Sometimes the policies we can know and follow in practice." In core narrative 8.1, the physician in South Africa said: "I think that's what everyone is aiming towards generally." If the physicians were that individually removed from global plans, what other disconnects exist?

An examination of barriers to knowing about the goals pits the individual versus the program. Society is made of individuals. Societal operations are carried out by individuals. A physician is an individual with professional responsibility to stay informed on important global initiatives, such as the MDGs and Stop TB, to access resources that will help them do their job as an individual. Familiarity with TB program guidance is important for knowing how to advocate for one's needs. Program representatives can serve as information brokers to physicians, but individuals also have the agency to 
access the internet and become informed. It is possible that not all individuals are motivated to be informed. Apathy or economic affluence could be reasons that individuals are not motivated. People may not care. They may be comfortable with their jobs as they are. It is also possible that program representatives may not supply physicians with information.

Beyond the individual, the UN may disrupt the flow of information. Since the UN governs global programs for TB, successfully administered programs must involve outreach or a process of recruitment. Physicians need to be informed of changes in indicators, targets, and goals. Considering the physicians involved in this study were not informed about the change from $70 / 85 \%$ rates, including the ones that showed they were invested in combatting TB, global programs need to be critically examined. How successful are global programs for TB if the physicians, who are directly carrying out the tasks needed to achieve the goals, are not informed? In some ways the recruitment process must be more than just outreach. Physicians need to be brought together to create essentially what one would consider a team.

Further examination illuminates a third layer in the relationship between individuals and programs: drug companies. Physicians expressed frustration over access to treatment. Out of the five physicians interviewed, three had access to bedaquiline and one to delamanid. Ironically, the physician in South Africa, who had access to bedaquiline, pointed out that delamanid was being unreasonably controlled by Otsuka, a company in Japan, while the Japanese physician with access to delamanid complained about accessing a drug called capreomycin. This warrants the examination of drug companies. Drug pricing makes some drugs out of reach for national budgets. Considering Otsuka has been described as elusive and unwilling to make delamanid accessible, drug companies appear to act as obstructionists to treatment (Médecins Sans Frontières 2016). Inefficiency is linked to the drug approval process, but there are ethical implications to intentionally resisting distribution of new medicines. 
Systematic collaboration is lacking across the individual, global programs, and drug companies, that undoubtedly leads to frustration.

Returning to goal achievement, it is important to consider that none of the countries involved in this study completed their goal for DR-TB. Success was not achieved globally for the $100 / 75 \%$ DR-TB goals included in this study. On a global scale, $90 \%$ of newly notified MDR-TB or rifampicin-resistant patients were started on treatment, and only 50\% of MDR-TB patients were successfully treated in 2014 (World Health Organization 2015). The physician in South Africa explained that nobody is able to achieve more than a $50 \%$ treatment success rate for DR-TB. However, none of the other doctors admitted this. If the physician in South Africa's statement is true, why are the other physicians not drawing attention to this? Is there shame involved with not being able to treat DR-TB cases? Do physicians care? After speaking with the physician in South Africa, it seems like the goals for DR-TB are perceived as unrealistic. If this was the case, one may wonder why the physician chose to invest in TB anyways. Perhaps for the physician in South Africa it is because the physician recognizes that global programs are not helpful. Maybe they believe they have to operate outside global programs altogether. Perhaps the UN consensus model, although powerful, operates too slowly to match the gravity of DR-TB burden.

In response to this disconnect, the message of this research is as follows: the WHO and the UN needed to be more connected to individuals. Both bodies could either encourage physician behavior with law, or incentivize with payment strategies. The MDGs and Stop TB are not coercive; however there is a sense of shame involved for people that are not able to achieve their goals. Because the MDGs and Stop TB operate at an international level, politics and data fabrication inevitably become involved. If individuals are not necessarily bound, educated, or enlightened by the global programs, then that is a problem that needs more attention. With the weakness of people not following global guidance, this translates into more harm. Alternatively, creating unreasonable guidance translates to harm as well, by 
fostering cynicism and eroding respect for global programs. Complications that exist at the intersection between the individual and the program are an area that deserves future research.

Although the DR-TB goals were not met, some success was achieved for regular TB. For instance, the MDG target to halt and reverse TB incidence was achieved globally (World Health Organization 2015). Also, mortality has fallen $47 \%$ since 1990 , with nearly all improvement taking place since the MDGs were set (World Health Organization 2015). Related to the countries involved in this research, three of the 2015 targets (for incidence, prevalence and mortality) were met in China, India, and Vietnam (World Health Organization 2015). Even so, TB still ranks alongside HIV as a leading cause of death worldwide, and will continue this way if global efforts to end TB do not progress (World Health Organization 2015). 


\section{Bibliography}

Abdel Aziz, Mohamed. 2003. "Guidelines for Surveillance of Drug Resistance in Tuberculosis." Second Edition. Geneva: World Health Organization. WHO Library Cataloguing-in-Publication Data. file://C:/Users/Hannah/Desktop/TB\%20Thesis/sources/2.\%20WHO/Abdel.pdf.

Fan, Victoria Y., and William D. Savedoff. 2014. "The Health Financing Transition: A Conceptual Framework and Empirical Evidence." Social Science \& Medicine 105 (March): 112-21. doi:10.1016/j.socscimed.2014.01.014.

Farmer, Paul. 2003. Pathologies of Power: Health, Human Rights, and the New War on the Poor. California Series in Public Anthropology 4. Berkeley: University of California Press.

-. 2013. Reimagining Global Health: An Introduction. California Series in Public Anthropology, v. 26. Berkeley: University of California Press.

Grant, Alison, Philip Gothard, and Guy Thwaites. 2008. "Managing Drug Resistant Tuberculosis.” BMJ: British Medical Journal 337 (7669): 564-69.

Howard, Andrea A., Robert S. Klein, Ellie E. Schoenbaum, and Marc N. Gourevitch. 2002. "Crack Cocaine Use and Other Risk Factors for Tuberculin Positivity in Drug Users." Clinical Infectious Diseases 35 (10): 1183-90.

Kelly, Patricia. 1999. "Isolation and Stigma: The Experience of Patients with Active Tuberculosis." Journal of Community Health Nursing 16 (4): 233-41.

Mahajan, Rajiv. 2013. "Bedaquiline: First FDA-Approved Tuberculosis Drug in 40 Years." International Journal of Applied and Basic Medical Research 3 (1): 1-2. doi:10.4103/2229-516X.112228.

Malthus, Thomas. 1798. "An Essay on the Principle of Population, As it Effects the Future Improvement of Society with Remarks on the Speculations of Mr. Godwin, M. Condorcet, and other writers. London, printed for J. Johnson, in ST. Paul'S Church-Yard, 1798." St. Paul's Church-Yard, London.

Médecins Sans Frontières. 2013. “A DR-TB Manifesto From Patients and Caregivers.” Alert.

—. 2016. "DR-TB DRUGS UNDER THE MICROSCOPE." 4 edition. Geneva, Switzerland http://www.msf.org/sites/msf.org/files/dr-tb_drugs_under_the_microscope.pdf.

Monedero, Ignacio, Jose A. Caminero, Rajita Bhavaraju, and Adrian Sanchez-Montalva. 2016. "The Changing Landscape in Drug Resistant-Tuberculosis: An Analysis of Recent Advances." Expert Review of Respiratory Medicine 10 (6): 603-6. doi:10.1586/17476348.2016.1164042.

Morgan, David L. 2007. "Paradigms Lost and Pragmatism Regained Methodological Implications of Combining Qualitative and Quantitative Methods." Journal of Mixed Methods Research 1 (1): 48-76. doi:10.1177/2345678906292462.

Murray, Christopher J L. 2014. "Global, Regional, and National Incidence and Mortality for HIV, Tuberculosis, and Malaria during 1990-2013: A Systematic Analysis for the Global Burden of Disease Study 2013." The Lancet 384 (no. 9947): 1005-70. 
Omran, Abdel R. 1971. "The Epidemiologic Transition: A Theory of the Epidemiology of Population Change." The Milbank Memorial Fund Quarterly 49 (4): 509. doi:10.2307/3349375.

Popkin, Barry M. 1994. "The Nutrition Transition in Low-Income Countries: An Emerging Crisis." Nutrition Reviews 52 (9): 285-98. doi:10.1111/j.1753-4887.1994.tb01460.x.

Riessman, Catherine Kohler. 1993. Narrative Analysis. 1st edition. Newbury Park, CA: SAGE Publications, Inc.

Rogers, Anissa. 2013. Human Behavior in the Social Environment. 3 edition. New York: Routledge.

Sachs, Jeffrey D. 2012. "Achieving Universal Health Coverage in Low-Income Settings." The Lancet 380 (9845): 944-47. doi:10.1016/S0140-6736(12)61149-0.

Sepkowitz, Kent A. 1996. “How Contagious Is Tuberculosis?” Clinical Infectious Diseases 23 (5): 954-62.

Spence, D. P. S., J. Hotchkiss, C. S. D. Williams, and P. D. O. Davies. 1993. "Tuberculosis and Poverty." BMJ: British Medical Journal 307 (6907): 759-61.

United Nations General Assembly. 2000. "Millennium Development Declaration.” http://www.un.org/millennium/declaration/ares552e.pdf.

—. 2016. "United Nations Millennium Development Goals." 2016. Accessed April 23. http://www.un.org/millenniumgoals/aids.shtml.

World Bank. 1993. "World Development Report 1993." New York: Oxford University Press. https://openknowledge.worldbank.org/handle/10986/5976.

-. 2010. "WDI 2010 | Data." 2014. Accessed December 3. http://data.worldbank.org/datacatalog/world- development-indicators/wdi-2010.

-. 2015. "Human Development Index (HDI) | Human Development Reports." 2016. Accessed April 24. http://hdr.undp.org/en/content/human-development-index-hdi.

World Health Organization. 2009. Management of MDR-TB: A Field Guide, a Companion Document to Guidelines for the Programmatic Management of Drug-Resistant Tuberculosis. World Health Organization. http://whqlibdoc.who.int/publications/2009/9789241547765_eng.pdf.

-. 2010. "The Global Plan to Stop TB 2011-2015." StopTB.org. http://www.stoptb.org/assets/ documents/global/plan/TB_GlobalPlanToStopTB2011-2015.pdf.

-. 2013. "Definitions and Reporting Framework for Tuberculosis - 2013 Revision." who.int. http://apps.who.int/iris/bitstream/10665/79199/1/9789241505345_eng.pdf.

-. 2015. World Health Organization. 2015. "2015 Global Tuberculosis Report." http://www.who.int/tb/publications/global_report/gtbr2015_executive_summary.pdf. 


\section{Appendix A}

\section{Core Narratives}

Japan
\begin{tabular}{|l|}
\hline \multicolumn{1}{|c|}{ Core Narrative 4.1} \\
\hline Question \\
\hline Have you heard of the Millennium Development Goals? Do you think they were effective? \\
\hline Orientation \\
\hline $\begin{array}{l}\text { Japanese Tuberculosis control program is very very stable. And it's very weakly influenced by the global } \\
\text { trend. }\end{array}$ \\
\hline $\begin{array}{l}\text { Some doctors were working in this research institute, of course involved in the Millennium Development } \\
\text { Goal, especially for the technical assistance to Cambodia and Myanmar. }\end{array}$ \\
\hline I myself was involved in the prevalence survey in Cambodia. \\
\hline Complicating Action \\
\hline But the Millennium Development Goal, I wasn't really involved in the MDG. \\
\hline Resolution \\
\hline Japanese TB control programs went on almost independently from the MDG.
\end{tabular}

\begin{tabular}{|l|}
\hline \multicolumn{1}{|c|}{ Core Narrative 4.2} \\
\hline Question \\
\hline Have you heard of the Global Plan to Stop TB? Do you think it is an effective plan? \\
\hline Orientation \\
\hline Through pre-DOTS you mean? \\
\hline Pre-DOTS. That is a strategy in the TB control program that is abdicated by the WHO. \\
\hline $\begin{array}{l}\text { In other words they work for the tuberculosis control. And with that effective tuberculosis control, } \\
\text { global control started from 1994. }\end{array}$ \\
\hline Complicating Action \\
\hline But now the Stop TB person says no more DOTs. New program activities. \\
\hline But there are some countries where DOTs is not implemented at yet. \\
\hline Resolution \\
\hline Without the idea of DOTs I'm afraid the program will collapse completely. \\
\hline
\end{tabular}




\begin{tabular}{|l|}
\hline \multicolumn{1}{|c|}{ Core Narrative 4.3} \\
\hline Question \\
\hline Do you work in a national TB program? Can you describe how that program functions? \\
\hline Orientation \\
\hline Only ten percent of my time. \\
\hline Part because most of my work is clinical work. \\
\hline I am a member of a national advisory group for public health. In the part of tuberculosis control. \\
\hline Complicating Action \\
\hline $\begin{array}{l}\text { This research institute often cooperates the document with support the ideas. To make the scientific } \\
\text { evidence, or not scientific evidence, but the situational analysis of TB control program and the TB } \\
\text { situation in Japan. }\end{array}$ \\
\hline Resolution \\
\hline For that kind of research I am sometimes involved. \\
\hline
\end{tabular}

\begin{tabular}{|l|}
\hline \multicolumn{1}{|c|}{ Core Narrative $\mathbf{4 . 4}$} \\
\hline Question \\
\hline Do you know your country's goals for TB? \\
\hline Orientation \\
\hline My contribution will be very small. \\
\hline In Japan Ministry of Health and Welfare and Labour make the national policy. \\
\hline $\begin{array}{l}\text { It is quite different from United States or other countries. United States there are many specialists } \\
\text { within CDC. }\end{array}$ \\
\hline Complicating Action \\
\hline But in Japan, within the ministry there is no specialist. \\
\hline Resolution \\
\hline $\begin{array}{l}\text { So they request the information from this institute and other departments. And we contribute in that } \\
\text { way. And advisory committee will make the overall direction or overall pathway for the tuberculosis } \\
\text { control. }\end{array}$ \\
\hline
\end{tabular}

\begin{tabular}{|l|}
\hline \multicolumn{1}{|c|}{ Core Narrative 4.5} \\
\hline Question \\
\hline Are you able to effectively treat all drug-resistant TB cases you encounter? \\
\hline Orientation \\
\hline In one sense clinically. \\
\hline Many of the different cases come to our hospital and we treat. \\
\hline Complicating Action \\
\hline Sometimes we fail. Sometimes we succeed. \\
\hline Before difficult tuberculosis there are many cases who are usual MDR. \\
\hline Resolution \\
\hline These cases can be treated not in a specialized hospital, but in other hospitals. \\
\hline
\end{tabular}




\begin{tabular}{|c|}
\hline Core Narrative 4.6 \\
\hline Question \\
\hline Do you have access to bedaquiline? \\
\hline Orientation \\
\hline Delamanid is available. \\
\hline $\begin{array}{l}\text { And in Japan bedaquiline. But bedaquiline phase two trial for the Japanese patient is now starting. And it } \\
\text { will be available in three or four years later. }\end{array}$ \\
\hline Complicating Action \\
\hline Capreomycin is not available. That is a very big problem. \\
\hline $\begin{array}{l}\text { Janssen Pharmaceutical Company was not so interested in sharing bedaquiline in Japan at the beginning } \\
\text { because in Japan the market is small. }\end{array}$ \\
\hline We need the information, for example whether we can use bedaquiline and delamanid together. \\
\hline Resolution \\
\hline But that study is going on under the umbrella of National Institute of Health in United States. \\
\hline $\mathrm{Dr}$ _ is now more interested in newer drug. \\
\hline Japan is small scale. If other institute is doing the same study we probably cannot compete. \\
\hline $\begin{array}{l}\text { So bedaquiline is really going to be essential to future treatment? No. No. No. Definitely no. But it will } \\
\text { play essential role for treatment of XDR. XDR. Extensively drug resistant tuberculosis. And bedaquiline } \\
\text { will be the center block. But it will not be used together with the rifampicin. But usual tuberculosis } \\
\text { probably it will not be used. }\end{array}$ \\
\hline
\end{tabular}

\begin{tabular}{|l|}
\hline \multicolumn{1}{|c|}{ Core Narrative 4.7} \\
\hline Question \\
\hline Anymore information I should know? \\
\hline Orientation \\
\hline $\begin{array}{l}\text { You know that the global epidemiology of tuberculosis, where it is prevalent? In African countries and } \\
\text { South Asian countries. }\end{array}$ \\
\hline MDR tuberculosis is more prevalent in the former Soviet Union and China. \\
\hline United States are playing a big role for the support to these countries. \\
\hline Japan works together with the Philippines and Myanmar and Cambodia. \\
\hline Complicating Action \\
\hline In this country problem with tuberculosis it's so small. It's not so big. \\
\hline Resolution \\
\hline I'm sorry. Ah. So I wonder why you are interested in them, global TB for the global programs? \\
\hline
\end{tabular}




\begin{tabular}{|l|}
\hline \multicolumn{1}{|c|}{ Core Narrative 4.8 } \\
\hline Question \\
\hline $\begin{array}{l}\text { MDR TB and XDR TB are very intensive treatment-wise and people don't want to spend money on } \\
\text { that because it only helps a few people and it takes a long amount of time for the treatment to work. }\end{array}$ \\
\hline Orientation \\
\hline Usual, not MDR, usual tuberculosis programs, anti TB drug is cheap. \\
\hline MDR tuberculosis is very different. It's very expensive. \\
\hline Once patient is cured he is cured. No more treatment. \\
\hline $\begin{array}{l}\text { Even though it is very expensive and may not be so cost effective, especially when new drugs } \\
\text { bedaquiline and delamanid are very very very expensive. }\end{array}$ \\
\hline $\begin{array}{l}\text { I was involved in tuberculosis control for the past twenty years and at the beginning I thought it is a very } \\
\text { cost effective and we can continue in the country. }\end{array}$ \\
\hline Complicating Action \\
\hline $\begin{array}{l}\text { But after the year } 2000 \text { when the WHO more focuses on MDR-TB and the private sector and I was afraid } \\
\text { we cannot continue because of its high cost. }\end{array}$ \\
\hline Resolution \\
\hline $\begin{array}{l}\text { Fortunately we can get the Gate's Foundation gave to the Global Fund supported so much for the } \\
\text { tuberculosis control so we could continue for the MDR-TB. }\end{array}$ \\
\hline But global funded going to finish nearly. So I am wondering whether we can continue or not. \\
\hline $\begin{array}{l}\text { And activities of global fund might have spoiled some persons. Spoiled means that we might not be able } \\
\text { to continue what could be done. }\end{array}$ \\
\hline
\end{tabular}

\section{China}

\begin{tabular}{|l|}
\hline \multicolumn{1}{|c|}{ Core Narrative $\mathbf{5 . 1}$} \\
\hline Question \\
\hline Have you heard of the Millennium Development Goals? Do you think they were effective? \\
\hline Orientation \\
\hline Yes. Yes. Yes. \\
\hline Yes. Of course. It is effective I think. \\
\hline Complicating Action \\
\hline $\begin{array}{l}\text { Sometimes it is difficult to do according to this project around the world. I think sometimes it is very } \\
\text { difficult to do TB treatment in very remote countryside. }\end{array}$ \\
\hline You know that. The DOTs, the MDR-TB control it is very difficult. \\
\hline Resolution \\
\hline So I don't know if we can get to the goal or not. \\
\hline
\end{tabular}




\begin{tabular}{|l|}
\hline \multicolumn{1}{|c|}{ Core Narrative $\mathbf{5 . 2}$} \\
\hline Question \\
\hline Have you heard of the Global Plan to Stop TB? Do you think it is an effective plan? \\
\hline Orientation \\
\hline Yes. Stop TB yes. \\
\hline Sure. It's effective. It's effective the project I think. \\
\hline Complicating Action \\
\hline If we do it will be effective. \\
\hline Resolution \\
\hline $\begin{array}{l}\text { I think the project it have some reputations for the diagnosis for MDR-TB detection and directly } \\
\text { observed treatment. I think that directly observed treatment also for MDR-TB it works. }\end{array}$ \\
\hline
\end{tabular}

\begin{tabular}{|c|}
\hline Core Narrative 5.3 \\
\hline Question \\
\hline Do you work in a national TB program? Can you describe how that program functions? \\
\hline Orientation \\
\hline In China we have a very strong network of TB. \\
\hline $\begin{array}{l}\text { The government they set up the CDC related network for surveillance control and management and give } \\
\text { the drug free. }\end{array}$ \\
\hline Every data from hospital have to report to the CDC. \\
\hline $\begin{array}{l}\text { Maybe the MDR-TB they will also give free. However if the other region maybe just give some } \\
\text { reimbursement. }\end{array}$ \\
\hline There's a lot of new diagnostic technique to diagnose MDR-TB. \\
\hline We published some papers for molecular detection. \\
\hline In every TB hospital in China have the, I mean every CDC TB hospitals they have Xpert. \\
\hline The regiment now is the same as WHO guidelines recommend. So I think it works. \\
\hline Complicating Action \\
\hline $\begin{array}{l}\text { According to the research paper published last year in New England Journal of Medicine for China CDC } \\
\text { they finish a survey for just strains from all over China they found that ten percent of the patients MDR- } \\
\text { TB. In all MDR-TB patient ten percent are XDR-TB. That means almost one percent of the TB patient are } \\
\text { XDR-TB. It is very difficult to treat. }\end{array}$ \\
\hline Resolution \\
\hline $\begin{array}{l}\text { Maybe what we need some new drug but it is very difficult for the patient to get the drug. Maybe very } \\
\text { very expensive. Maybe not large. So the availability and affordability is a problem for XDR-TB. However, } \\
\text { MDR-TB I think China we can do that. }\end{array}$ \\
\hline
\end{tabular}




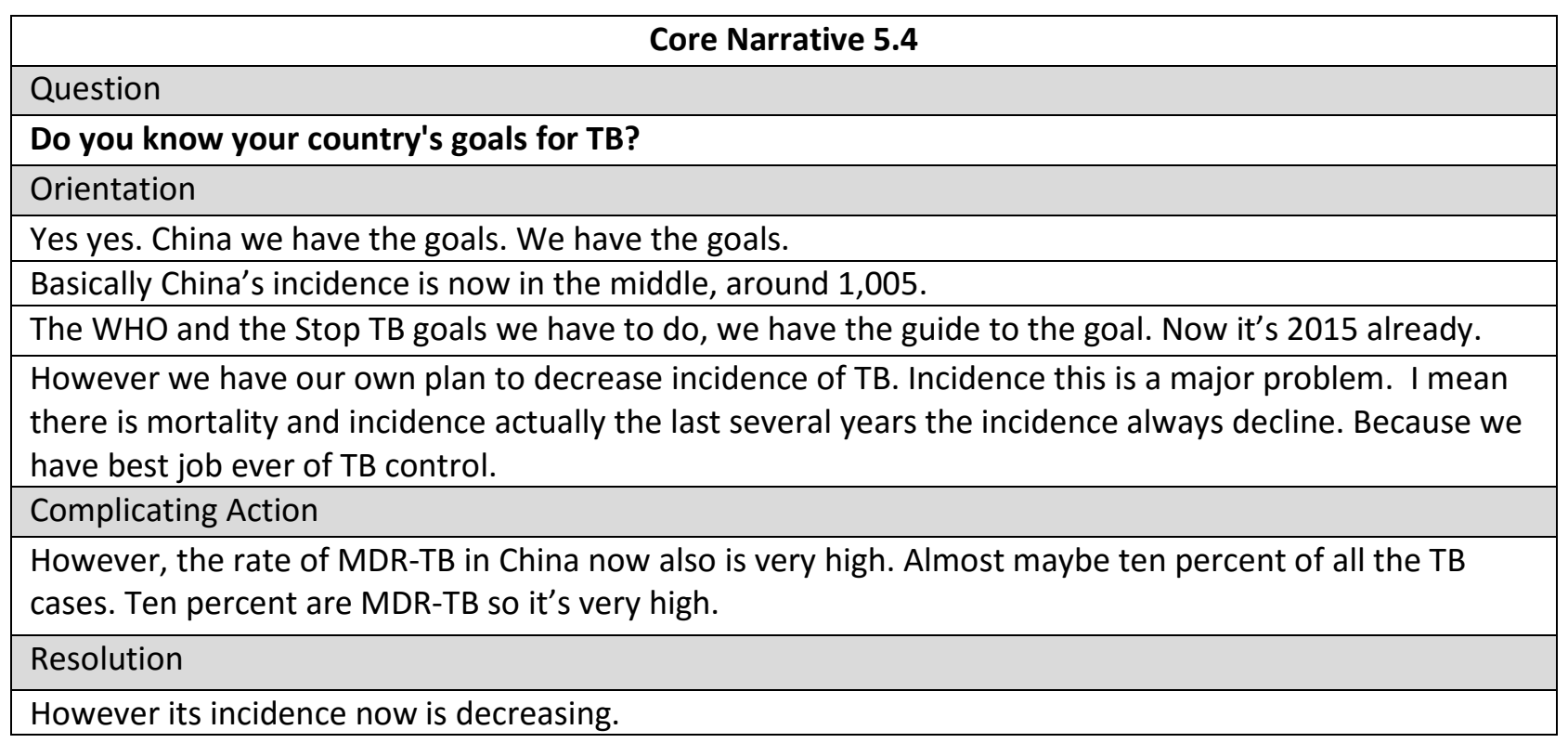

\begin{tabular}{|l|}
\hline \multicolumn{1}{|c|}{ Core Narrative $\mathbf{5 . 5}$} \\
\hline Question \\
\hline Are you able to effectively treat all drug-resistant TB cases you encounter? \\
\hline Orientation \\
\hline $\begin{array}{l}\text { Sure. Now we just take the community center drugs. Some effective first you add drug cures MDR-TB } \\
\text { most of the time the strains are resistant to most. }\end{array}$ \\
\hline The drug recently in China there's no different from in the United States and other country. \\
\hline Complicating Action \\
\hline You know now recently there is some new drug launched in United States. \\
\hline Resolution \\
\hline However it has not been launched in China already. \\
\hline
\end{tabular}

\begin{tabular}{|l|}
\hline \multicolumn{1}{|c|}{ Core Narrative 5.6} \\
\hline Question \\
\hline Do you have access to bedaquiline? \\
\hline Orientation \\
\hline Bedaquiline. You know the same. \\
\hline Complicating Action \\
\hline $\begin{array}{l}\text { The efficacy of bedaquiline now is controversial. There is some concern about safety. You know that. It } \\
\text { hasn't passed. }\end{array}$ \\
\hline The price is also very expensive. In China there are lots of TB patients who may need this drug. \\
\hline Resolution \\
\hline $\begin{array}{l}\text { You know I think some drugs are now the clinical trial has been finished. With which I could this year, } \\
\text { August here have access to these new drugs. The Janssen Company and also there's some other new } \\
\text { drugs now also now in the whole world have the clinical trial for that. }\end{array}$ \\
\hline
\end{tabular}


Vietnam

\begin{tabular}{|l|}
\hline \multicolumn{1}{|c|}{ Core Narrative 6.1} \\
\hline Question \\
\hline Have you heard of the Millennium Development Goals? Do you think they were effective? \\
\hline Orientation \\
\hline Of TB? I hear about that. Yea. \\
\hline I think so. \\
\hline Complicating Action \\
\hline Not directly impactful. \\
\hline Resolution \\
\hline I think it impacts our country. \\
\hline
\end{tabular}

\begin{tabular}{|l|}
\hline \multicolumn{1}{|c|}{ Core Narrative 6.2} \\
\hline Question \\
\hline Have you heard of the Global Plan to Stop TB? Do you think it is an effective plan? \\
\hline Orientation \\
\hline I heard about that but I don't remember in detail. \\
\hline I think sometimes we can complete in my country. \\
\hline Complicating Action \\
\hline I don't work in the TB management program directly. So I just work with TB patients. \\
\hline Resolution \\
\hline Sometimes the policies we can know and follow in practice. \\
\hline
\end{tabular}

\begin{tabular}{|c|}
\hline Core Narrative 6.3 \\
\hline Question \\
\hline Do you work in a national TB program? Can you describe how that program functions? \\
\hline Orientation \\
\hline $\begin{array}{l}\text { We have MDTB headquarter in Hanoi. Then in each province we have TB center. All TB and lung disease } \\
\text { hospital. }\end{array}$ \\
\hline $\begin{array}{l}\text { Some province have TB center and some province have TB hospital. And some province has TB unit or } \\
\text { TB center. }\end{array}$ \\
\hline $\begin{array}{l}\text { All the data profiles from each district TB unit they can send to the TB center like that, of the profiles. } \\
\text { Then they send the data to central TB headquarter. }\end{array}$ \\
\hline $\begin{array}{l}\text { Below the TB center province we have district TB unit in each district of the province. And the district TB } \\
\text { unit has networks in community. }\end{array}$ \\
\hline $\begin{array}{l}\text { First two months intensifying treatment we can receive directly in district TB unit like DOTs. And after } \\
\text { that they can receive the TB drugs in community. }\end{array}$ \\
\hline Complicating Action \\
\hline They have to go to the TB office in their province. Not TB, medical office in community. \\
\hline Resolution \\
\hline $\begin{array}{l}\text { Very near their home. And they can go to there and receive TB drug there. We perform DOTs for all TB } \\
\text { patients in my country. }\end{array}$ \\
\hline
\end{tabular}




\begin{tabular}{|l|}
\hline \multicolumn{1}{|c|}{ Core Narrative 6.4} \\
\hline Question \\
\hline Do you know your country's goals for TB? \\
\hline Orientation \\
\hline Yes. \\
\hline Complicating Action \\
\hline We can cure the patients more than 85\%. \\
\hline Resolution \\
\hline We finished it. This is from my city. \\
\hline
\end{tabular}

\begin{tabular}{|c|}
\hline Core Narrative 6.5 \\
\hline Question \\
\hline Are you able to effectively treat all drug-resistant TB cases you encounter? \\
\hline Orientation \\
\hline Yea. In my hospital we have a department for MDR-TB. \\
\hline When their results come back and if they are MDR-TB patients the patients can receive treatment. \\
\hline $\begin{array}{l}\text { The doctor can treat them MDR treatment finalized by national TB program. And when they are okay } \\
\text { they are totally done with the drugs, they can move, they can be referred to local TB units and receive } \\
\text { the drug there. }\end{array}$ \\
\hline Complicating Action \\
\hline $\begin{array}{l}\text { We have an MDTB project for the country so we receive the drugs from NTB and we have network in } \\
\text { our city so I don't know other drugs. }\end{array}$ \\
\hline Resolution \\
\hline $\begin{array}{l}\text { We have drugs supplied to each TB unit and then when the patients refer to HIV TB unit we can continue } \\
\text { treatment there. }\end{array}$ \\
\hline
\end{tabular}

\begin{tabular}{|l|}
\hline \multicolumn{1}{|c|}{ Core Narrative 6.6} \\
\hline Question \\
\hline Do you have access to bedaquiline? \\
\hline Orientation \\
\hline I don't involve in the MDR program. But I know some second line drugs. \\
\hline That drug is not available in my city. \\
\hline Complicating Action \\
\hline I don't know when it is coming. You know sorry because I am not in MDR program. \\
\hline Resolution \\
\hline $\begin{array}{l}\text { If my patients have their experiences they are MDR-TB patient I can refer them to the MDR program and } \\
\text { other doctor can take care of them. }\end{array}$ \\
\hline
\end{tabular}


India

\begin{tabular}{|l|}
\hline \multicolumn{1}{|c|}{ Core Narrative 7.1} \\
\hline Question \\
\hline Have you heard of the Millennium Development Goals? Do you think they were effective? \\
\hline Orientation \\
\hline Yes. Millennium Development Goals have been framed during our TB training of the TB control program. \\
As program manager we have all been coordinating several program roles standardized by the \\
Millennium Development Goals. DOTs. \\
\hline Complicating Action \\
\hline Even though they're all meeting separate marks, still not fully achieved. \\
\hline Resolution \\
\hline Everyone is striving forward to achieve all the elements of these development goals. \\
\hline
\end{tabular}

\begin{tabular}{|l|}
\hline \multicolumn{1}{|c|}{ Core Narrative 7.2} \\
\hline Question \\
\hline Have you heard of the Global Plan to Stop TB? Do you think it is an effective plan? \\
\hline Orientation \\
\hline $\begin{array}{l}\text { This was also a part of training as program manager. And we would talk about various funding agencies } \\
\text { for this TB control program especially over here. So these programs are all being conducted with the } \\
\text { help of international funding agencies. As part of that we have been hearing information about this. }\end{array}$ \\
\hline $\begin{array}{l}\text { Yes yes of course. It is effective because of the impact of giving for Stop TB control program it would be } \\
\text { advantageous especially in tribal areas. }\end{array}$ \\
\hline Complicating Action \\
\hline Without the available facilities we might not be able to reach. \\
\hline Resolution \\
\hline $\begin{array}{l}\text { With the funding from these agencies we could reach tribal areas and with the initial stage we were } \\
\text { trying to get service to those who were coming to us. Now we are in a position, a good position to go to } \\
\text { the place with those people who are in need of TB service. }\end{array}$ \\
\hline
\end{tabular}




\begin{tabular}{|l|}
\hline \multicolumn{1}{|c|}{ Core Narrative 7.3} \\
\hline Question \\
\hline Do you work in a national TB program? Can you describe how that program functions? \\
\hline Orientation \\
\hline Yes. It was when I joined a national TB program. \\
\hline $\begin{array}{l}\text { This program was implemented at our training to all medical officers, or primary leaders, or lab } \\
\text { technicians. After that we are also conducting so many programs, raise awareness among general public } \\
\text { and the NGOs. We are conducting so many training programs for all these groups. }\end{array}$ \\
\hline $\begin{array}{l}\text { We will conduct district level programs, development programs then get the involvement of the political } \\
\text { ministers and other people who are prominent in the society to become the ambassadors of this } \\
\text { program. }\end{array}$ \\
\hline Complicating Action \\
\hline This program covers almost all of India. \\
\hline Resolution \\
\hline $\begin{array}{l}\text { So in every government hospital from medical college to primary health center all are following the } \\
\text { state guidelines as described in the revised TB national control program. }\end{array}$ \\
\hline
\end{tabular}

\begin{tabular}{|l|}
\hline \multicolumn{1}{|c|}{ Core Narrative 7.4} \\
\hline Question \\
\hline Do you know your country's goals for TB? \\
\hline Orientation \\
\hline $\begin{array}{l}\text { Yes. The ultimate goal is to have a TB free India. And initially we set two objectives for achieving this } \\
\text { goal. }\end{array}$ \\
\hline Complicating Action \\
\hline That was to achieve a cure rate of 85\% and a detection rate of 70\%. \\
\hline Resolution \\
\hline $\begin{array}{l}\text { With the involvement of international agencies and the Global Plan to Stop TB, and the Millennium } \\
\text { Development Goals we have reached our objectives as 90\% detection as well as cure rate. }\end{array}$ \\
\hline And we are almost achieving this goal consistently for the whole province in a year. \\
\hline
\end{tabular}




\begin{tabular}{|l|}
\hline \multicolumn{1}{|c|}{ Core Narrative 7.5} \\
\hline Question \\
\hline Are you able to effectively treat all drug-resistant TB cases you encounter? \\
\hline Orientation \\
\hline $\begin{array}{l}\text { Yes. Our state is not the first district to have national program for drug resistant tuberculosis in India. } \\
\text { And then we kind of established successfully and are conducting successfully and it has spread to other } \\
\text { states also. }\end{array}$ \\
\hline We have detected 163 MDR-TB patients and we have put 140 of them on treatment. \\
\hline $\begin{array}{l}\text { The remaining } 23 \text { means ten have gone to other districts after diagnosis and they were from other } \\
\text { states. So we sent them to their place. }\end{array}$ \\
\hline Complicating Action \\
\hline $\begin{array}{l}\text { Seven died before starting treatment because we were using slow culture. It would take two to three } \\
\text { months to get their results unfortunately. }\end{array}$ \\
\hline $\begin{array}{l}\text { And six persons were not willing to start initial drug treatment. They were not willing. They were fed up } \\
\text { with primary drugs. And after failure of the primary treatment they said stop. }\end{array}$ \\
\hline Resolution \\
\hline $\begin{array}{l}\text { Now we are using more efficient like line probe assay in which there is a result in ten days. So we are } \\
\text { getting more of these tools and we are starting earlier dose. }\end{array}$ \\
\hline $\begin{array}{l}\text { From } 2008 \text { onwards and we now we have } 61 \text { patients who have been through it. } 61 \text { cured. Then some of } \\
\text { the patients died. Some defaulted. There was one patient XDR-TB. Extensively drug resistant TB. As we } \\
\text { put him on treatment he is going on well now. He's on treatment. }\end{array}$ \\
\hline
\end{tabular}

\begin{tabular}{|l|}
\hline \multicolumn{1}{|c|}{ Core Narrative 7.6} \\
\hline Question \\
\hline Do you have access to bedaquiline? \\
\hline Orientation \\
\hline Not yet. As of now it's now available in any hospitals or even private hospitals not available. \\
\hline Complicating Action \\
\hline $\begin{array}{l}\text { It's not actually permitted to sell for safety reasons. Most of them will not be able to go for delamanid } \\
\text { because of severe side effects. And many of them are literally poor. }\end{array}$ \\
\hline Resolution \\
\hline We are successfully implementing it since the last four months. It's going on well. \\
\hline $\begin{array}{l}\text { They will come in and then we will give them their supplements, a checkup is done, any problem is } \\
\text { discussed, and we'll see them next month. }\end{array}$ \\
\hline
\end{tabular}




\begin{tabular}{|l|}
\hline \multicolumn{1}{|c|}{ Core Narrative 7.7} \\
\hline Question \\
\hline Anymore information I should know? \\
\hline Orientation \\
\hline We are optimistic. We hope we will be able to overcome this problem one day. \\
\hline Complicating Action \\
\hline Not in my life. Maybe after that. \\
\hline Resolution \\
\hline But we are optimistic. \\
\hline
\end{tabular}

\section{South Africa}

\begin{tabular}{|l|}
\hline \multicolumn{1}{|c|}{ Core Narrative 8.1 } \\
\hline Question \\
\hline Have you heard of the Millennium Development Goals? Do you think they were effective? \\
\hline Orientation \\
\hline Mhm. \\
\hline $\begin{array}{l}\text { I guess in a way. I suppose you know the goal to reduce new TB infections and deaths from TB does } \\
\text { impact our work a little. }\end{array}$ \\
\hline Complicating Action \\
\hline But I think that's what everyone is aiming towards generally. \\
\hline Resolution \\
\hline $\begin{array}{l}\text { So whether the goal is there or not I think we just end up doing the same thing. So I'm not sure it } \\
\text { influences the local level. }\end{array}$ \\
\hline
\end{tabular}

\begin{tabular}{|c|}
\hline Core Narrative $\mathbf{8 . 2}$ \\
\hline Question \\
\hline Have you heard of the Global Plan to Stop TB? Do you think it is an effective plan? \\
\hline Orientation \\
\hline Mhm. \\
\hline $\begin{array}{l}\text { I guess it's helped to raise awareness of TB and the need to do something about it. So I think on a more } \\
\text { global scale it's perhaps increased funding for tuberculosis. It's increased research and development } \\
\text { which then has filtered down and impacted us and what we do here. As an international organization } \\
\text { we're committed to fighting TB so we have all sorts of different interactions with different stakeholders } \\
\text { so we would support all those kinds of initiatives. And that's reflected in global programs. }\end{array}$ \\
\hline Complicating Action \\
\hline $\begin{array}{l}\text { And I guess in terms of working with national departments of health, particularly a place like South } \\
\text { Africa, it's a middle to low income country and so they might benefit from easier access to new drugs or } \\
\text { support for implementing new diagnostics in a country for example. }\end{array}$ \\
\hline Resolution \\
\hline $\begin{array}{l}\text { Rolling out gene Xpert, rolling out rapid diagnostics, you know access to the new drug bedaquiline, } \\
\text { that's probably because of this raised awareness and commitment to working with TB. }\end{array}$ \\
\hline
\end{tabular}




\begin{tabular}{|l|}
\hline \multicolumn{1}{|c|}{ Core Narrative 8.3} \\
\hline Question \\
\hline Do you work in a national TB program? Can you describe how that program functions? \\
\hline Orientation \\
\hline $\begin{array}{l}\text { I sort of work within one. Our project is very integrated with the department of health structure. We set } \\
\text { up this decentralized DR-TB care model which then now has been completely taken over by the } \\
\text { department of health. }\end{array}$ \\
\hline I connect with the doctors in all the primary healthcare clinics as well as the TB nurses in the TB rooms. \\
\hline I have connections with the department of health managers for this sub district. \\
\hline $\begin{array}{l}\text { I attend quite a few provincial department of health meetings and policy groups where they discuss new } \\
\text { policies to be rolled out in terms of TB management, diagnostics, etc. }\end{array}$ \\
\hline $\begin{array}{l}\text { In touch with lots of specialists working as clinicians in different places outside of _ but also the } \\
\text { provincial managers, health managers. }\end{array}$ \\
\hline $\begin{array}{l}\text { At the national level I attend quite a few national meetings on drug resistant TB and the TB programs. } \\
\text { On an annual basis there'Il usually be some kind of workshop or program where they discuss what's } \\
\text { happening with TB in South Africa. }\end{array}$ \\
\hline $\begin{array}{l}\text { I'Il meet doctors who run TB hospitals in other provinces for example. And you learn from each other } \\
\text { and you can influence each other and help to support each other too and move it forward. }\end{array}$ \\
\hline Complicating Action \\
\hline $\begin{array}{l}\text { I think that really requires a good working relationship with the department of health at the local level } \\
\text { and the national level. }\end{array}$ \\
\hline Resolution \\
\hline $\begin{array}{l}\text { So because we were interested in accessing the new drug bedaquiline, we became a part of the national } \\
\text { bedaquiline clinical access program which comes with sort of lots of different partners from across } \\
\text { South Africa, the department of health but also some NGOs and ours is one of them. }\end{array}$ \\
\hline
\end{tabular}

\begin{tabular}{|l|}
\hline \multicolumn{1}{|c|}{ Core Narrative 8.4} \\
\hline Question \\
\hline Do you know your country's goals for TB? \\
\hline Orientation \\
\hline I don't them off the top of my head. I'd guess it would be the same goals as most people want. \\
\hline Complicating Action \\
\hline To detect more than 70\% and cure more than 85\% of all TB cases and all DR-TB cases. \\
\hline Resolution \\
\hline $\begin{array}{l}\text { But I don't know anything more specific than that. Do you think any of the physicians you work with } \\
\text { would know that? I doubt it. }\end{array}$ \\
\hline
\end{tabular}




\begin{tabular}{|c|}
\hline Core Narrative 8.5 \\
\hline Question \\
\hline Are you able to effectively treat all drug-resistant TB cases you encounter? \\
\hline Orientation \\
\hline $\begin{array}{l}\text { No. Nobody is. Firstly we have a problem diagnosing all the cases so we can't treat them if we don't } \\
\text { know them. }\end{array}$ \\
\hline $\begin{array}{l}\text { In terms of effectively treating depends on whether you mean getting them on to treatment, we get } \\
90 \% \text { of our patients who are diagnosed on to treatment, so that's pretty good compared to the rest of } \\
\text { South Africa which is around } 50 \% \text {. }\end{array}$ \\
\hline $\begin{array}{l}\text { We have access to smear microscopy, culture, drug sensitivity testing using culture based phenotypic } \\
\text { conventional drug sensitivity testing, and line probe assay which is a more rapid genotypic testing } \\
\text { method. }\end{array}$ \\
\hline $\begin{array}{l}\text { And then there is university, so _in _ have access to genotyping so they usually do that more in research } \\
\text { settings rather than routinely so if you have a very specific case of discordance for example, discordant } \\
\text { results, then they'll go and genotype a sample. }\end{array}$ \\
\hline Complicating Action \\
\hline $\begin{array}{l}\text { Currently with the current standard MDR regiment that's available in South Africa the success rate is } \\
\text { about } 50 \% \text {. So the chance of you being cured is around } 50 \% \text {. }\end{array}$ \\
\hline $\begin{array}{l}\text { But line probe assay is not routine just as yet it's about to be this year. However if we request it } \\
\text { specifically then we can get it so you can motivate to get that test. }\end{array}$ \\
\hline Resolution \\
\hline $\begin{array}{l}\text { Our aim was to decentralize care to give that same treatment but to more people and that's what we've } \\
\text { achieved. We have not achieved more effective treatment. But that's one of the new things that we're } \\
\text { working on. That's one of our pilot projects. }\end{array}$ \\
\hline
\end{tabular}

\begin{tabular}{|l|}
\hline \multicolumn{1}{|c|}{ Core Narrative 8.6} \\
\hline Question \\
\hline Do you have access to bedaquiline? \\
\hline Orientation \\
\hline $\begin{array}{l}\text { We do I mean when the bedaquiline access program started in 2013, beginning in } 2013 \text { there was only } \\
\text { four sites in South Africa that initially got access to it, so _ was one of the sites so we were fortunate to } \\
\text { be part of that. But then it kind of expanded to more sites. }\end{array}$ \\
\hline Complicating Action \\
\hline $\begin{array}{l}\text { And now there's this next stage of rollout where they're trying to get it to all the provinces all the TB } \\
\text { hospitals across the country. }\end{array}$ \\
\hline Resolution \\
\hline $\begin{array}{l}\text { And so I'm very involved with the policy development there at the_level, so the provincial level, as to } \\
\text { how that's going to happen. So we do have access to bedaquiline which is lucky. The other countries } \\
\text { I've gone to, I think Japan was the only one doing clinical trials and all the rest hadn't been able to } \\
\text { even touch it. Yea I mean a lot of clinical trials have run in South Africa, especially in_so lots of people } \\
\text { are aiming to access it through clinical trials but we were able to access it through an access program } \\
\text { which was not a clinical trial it was more of an expanded access kind of program. And now it's being } \\
\text { registered by South Africa, the department of health wants to roll it out. }\end{array}$ \\
\hline
\end{tabular}




\begin{tabular}{|c|}
\hline Core Narrative 8.7 \\
\hline Question \\
\hline Anymore information I should know? \\
\hline Orientation \\
\hline $\begin{array}{l}\text { You might want to think about things like delamanid and access to delamanid because it's very close on } \\
\text { the back of bedaquiline but it's much more difficult it seems to access. They do have a compassionate } \\
\text { use program which I know some countries have applied to it and Otsuka themselves I feel are willing to } \\
\text { give the drug. }\end{array}$ \\
\hline Complicating Action \\
\hline $\begin{array}{l}\text { But because they have such stringent confidentiality controls on their protocol it means that a lot of } \\
\text { countries can't access it because within their local regulations you know they can't get over those } \\
\text { requirements. So Otsuka think their like giving it out as compassionate use but actually it's very difficult. } \\
\text { They're not helping countries to access it in that way. }\end{array}$ \\
\hline $\begin{array}{l}\text { They will come and do clinical trials in our settings, so they'll you know a few patients have been on } \\
\text { delamanid through clinical trials, but now that it's becoming registered in some places and now that it's } \\
\text { available through compassionate use the very same people they were testing it on aren't able to access } \\
\text { it and I think that's really unfair. }\end{array}$ \\
\hline Resolution \\
\hline That's something that we need to be focusing on a little bit more. \\
\hline
\end{tabular}

\begin{tabular}{|c|}
\hline Core Narrative 8.8 \\
\hline Question \\
\hline Who is controlling those two drugs primarily? Where are they based? \\
\hline Orientation \\
\hline The drug companies largely. \\
\hline $\begin{array}{l}\text { Otsuka's in Japan but Janssen I think are in Europe. I can't remember if it's Switzerland or Sweden. } \\
\text { Anyway but it's in Europe somewhere. But now that it's registered, once a country registers a drug then } \\
\text { the use is really not dependent on Janssen. So they can't restrict the use anymore. It's up to the country } \\
\text { regulatory authorities to do that. }\end{array}$ \\
\hline Complicating Action \\
\hline But with Otsuka because it's not yet been registered they want to control its use. \\
\hline Resolution \\
\hline And so they're really the ones who are you know effecting delamanid. \\
\hline
\end{tabular}

